\title{
A critical review on the environmental impact of manufacturing: a holistic perspective
}

\author{
Vasiliki Christina Panagiotopoulou ${ }^{1} \cdot$ Panagiotis Stavropoulos ${ }^{1} \cdot$ George Chryssolouris ${ }^{1}$
}

Received: 2 May 2021 / Accepted: 27 August 2021 / Published online: 7 September 2021

(C) The Author(s) 2021

\begin{abstract}
Manufacturing sector is considered to be the second highest contributor in greenhouse gases emissions in EU, secondary to energy sector. The environmental impact of products, processes, and infrastructures of manufacturing is defined as the mass equivalent of carbon dioxide emissions, also known as carbon footprint, because carbon dioxide accounts for the largest portion of greenhouse gases emissions. The aim of this review is to show the impact of manufacturing on carbon emissions and to investigate the importance of carbon emission factors on the carbon footprint of manufacturing. This was performed via (1) mapping and categorizing the sources of carbon emission at process, machine, and system level; (2) identifying the weight factor of carbon emissions factors via sensitivity analysis; and (3) determining which carbon emission factor has the heaviest contribution in carbon footprint calculation. In all examples of the sensitivity analysis, it was shown that carbon emission factor for electrical energy was the only contributing factor at process level while being the strongest at machine level. At system level, the strongest contributor was the carbon emission factor for material production. To reduce the carbon emissions, one must identify the tuneable parameters at process, machine, and system level, from material, machine tool, and energy point of view. However, the highest reduction in carbon footprint can be achieved by reducing the carbon emission factors of electrical energy using renewable power sources such as solar or wind and by reducing the carbon emission factors for material production using recycling materials as "raw" material.
\end{abstract}

Keywords Manufacturing $\cdot$ Process $\cdot$ Carbon footprint $\cdot$ Carbon emission factors $\cdot$ Sensitivity analysis

\section{Introduction}

Manufacturing is defined as the transformation of raw materials into products, being among the top human activities worldwide [1]. In general, human activities are responsible for increasing concentrations of greenhouse gases (GHG) which are linked to the rapid rise of global temperature. According to literature [2], the largest share of global greenhouses gases comes from the energy consumption $(73.2 \%)$, with the main contributor being the industrial sector. The latest analysis from European

George Chryssolouris

xrisol@1ms.mech.upatras.gr

1 Laboratory for Manufacturing Systems \& Automation, Department of Mechanical Engineering \& Aeronautics, University of Patras, 26504 Patras, Greece
Statistics (Eurostat) has placed manufacturing as the second highest contributor, second to energy sector that includes electricity, gas, steam, and air conditioning supply [3]. However, this definition of energy sector includes also demands from manufacturing sector. To address the urging issue of increasing carbon emissions, European Union (EU) has published directives for short-term sustainable growth [4] and long-term carbon neutral economy [5]. The short-term directives focus in decreasing the carbon emissions of products/services within EU, while the longer-term strategy aims to create a carbon neutral and circular economy in EU.

Carbon dioxide accounts for the largest share of greenhouse gases. In order to decrease the carbon emissions, the term of carbon footprint for all products and activities was introduced. The main definition of carbon footprint is the quantity of greenhouse gases expressed in terms of equivalent mass of carbon dioxide emitted by an individual, organization, process, product, or event within a specific 
boundary and is expressed in $\mathrm{kgCO}_{2}$-e [6]. There are standards and guidelines available for greenhouse gases and carbon footprint calculation, such as GHG protocol of World Resource Institute [7], ISO 14040 [8], and ISO 14064 [9].

Since industry is among the largest contributors of carbon dioxide emissions [10], several studies calculated the carbon emissions of processes, to investigate the order of magnitude of the carbon emissions $[11,12]$ to identify the carbon footprint-intensive steps $[13,14]$ and to optimize process for reduced carbon emissions [15-19]. According to the classification of Chryssolouris [1], the manufacturing processes can be either phase changing processes, which utilize not only electrical energy, but also other sources of energy such as natural gas, or non-phase changing processes, that primarily use electrical energy. The majority of carbon emissions is linked with the use of electrical energy and is therefore calculated by the product of energy consumed times a carbon emission factor. This carbon emission factor varies from country to country, or from area to area, since it is linked to the way electrical energy is generated [20]. A review and critical appraisal of the existing literature are missing, in order to identify the limitations of the current approaches, but also to formulate the methodology and highlight the importance of different components used in the calculation of carbon footprint for processes.

This review aims to investigate the environmental impact of manufacturing, by (1) collating the equations and approaches from literature, (2) formulating the general equations for carbon footprint calculation, regardless the process, and (3) identifying the impact of qualitative and quantitative parameters use the carbon footprint. The contents of this review are summarized in the following order: Section 2 includes the methodology for the performing of the literature review; Section 3 starts by defining key concepts of manufacturing processes and levels, followed by the main equations used for carbon footprint calculation at each level; Section 4 provides sensitivity analysis for three case studies (material removal, primary forming, and deforming); Section 5 includes the discussion, followed by the Section 6 and the conclusion of the work.

\section{Methods}

Literature search was conducted in Google scholar and Scopus to identify the papers to be included in this review with keywords: "process," "manufacturing," and "carbon emission calculation." This search resulted in 146 papers, which were later reviewed to ensure their relevance to the scope of this review (Fig. 1).
Articles were included based on the following criteria:

a) Type of process (material removal, primary forming, and deforming)

b) Calculation of carbon emissions using mathematical equations

At the end, 79 papers were included and divided according to the process addressed:

- Material removal ([12, 13, 16, 21-83])

- Primary forming $([20,84])$,

- Deforming ([28, 63, 85-92])

The following information were extracted from the papers and can be found in the Appendix 1:

a) Determination of the level of steps included in the carbon calculation (process level, machine level, system level)

b) Type of process

\section{General approach for carbon calculation in manufacturing}

\subsection{Definition of manufacturing processes and description of levels}

According to Chryssolouris et al [93], manufacturing is defined "as the transformation of materials and information into goods" to cover customer needs. Besides this, manufacturing is accompanied with carbon emissions, with each product/process related to a specific carbon footprint, based on the specific material, machine tool, and energy used.

Manufacturing can be divided into three main levels: process, machine, and system, according to whether the reference is on the process itself, with or without the aid of auxiliary equipment and lastly, if other processes are included, which are either related to the factory/industry level or material and tool production, disposal, and transportation.

At each level, the inputs are energy, materials, and tools/ equipment, and the outputs are products and carbon footprint of products (Fig. 2, Table 1). These parameters are classified into quantitative and qualitative parameters, depending on whether they are related to the source or emission factor or whether they are related to their value, respectively (Table 2).

\subsection{Carbon emissions at process level}

Carbon emissions from the process are mainly related to the energy consumed during the process $\left(E_{\text {process }}\right)$. The energy 
Fig. 1 Flowchart of present literature review, with categorization of papers in material removal, primary forming, and deforming processes

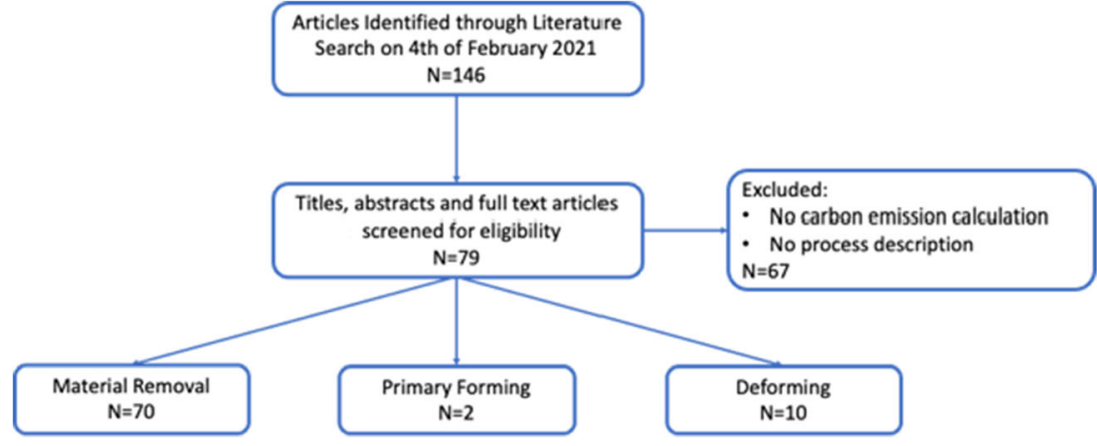

depends on the material and machine specifications and requirements. Energy can be generated from different sources and brought in different forms; however, in machine tools, the most frequent is electrical energy [1]. The carbon emission factor $\left(C E F_{\text {elec }}\right)$ depends on the source of power generation.

The carbon emissions of process are given by:

$C E_{\text {process }}=C E F_{\text {elec }} \cdot E_{\text {process }}$

$C E F_{\text {elec }}$ is related to the electrical energy generation source, while $E_{\text {process }}$ is a quantitative parameter, namely related to how much energy is needed to complete this process. $E_{\text {process }}$ depends on the raw material, the final product requirements, and the machine specifications, such as feed rate and process speed.

\subsection{Carbon emissions at machine tool level}

At the level of machine, the carbon emissions are given not only by the process, but also from the auxiliary equipment and consumption of tools and consumables:
$C E_{\text {machine }}=C E_{\text {process }}+C E_{\text {aux }}+C E_{\text {tool, cons }}+\sum_{i} C E_{i, \text { cons }}$

where $C E_{a u x}$ is the carbon emissions from auxiliary equipment (namely starting energy, basic energy, idle energy, and downtime energy), $C E_{\text {tool, cons }}$ carbon emissions from tool consumption, and $C E_{i, \text { cons }}$ carbon emissions from consumable consumption, where consumables can be lubricant, coolant, and chips.

Carbon emissions at machine level are also given by:

$$
\begin{aligned}
& C E_{\text {machine }}=C E F_{\text {elec }} \cdot E_{\text {process }}+C E F_{\text {elec }} \cdot E_{\text {aux }} \\
& +C E F_{\text {tool,cons }} \cdot E_{\text {tool,cons }}+\sum_{i} C E F_{i, \text { cons }} \cdot Q_{i, \text { cons }}
\end{aligned}
$$

where $C E F_{i, \text { cons }}$ is the carbon emission factor of tool consumption, $E_{\text {tool, }}$ cons energy required for tool consumption, $C E F_{i, \text { cons }}$ carbon emission factor of consumable consumption, and $Q_{i, \text { cons }}$ quantity of consumables consumed to complete the production of the final product.

Similarly, to the process level, some parameters are qualitative (related to the carbon emission factors) and quantitative

\begin{tabular}{|c|c|c|}
\hline Level & Description & Components included \\
\hline Process & Related to physical to the process itself & $\begin{array}{l}\text { Raw material } \\
\text { Process energy } \\
\text { Process time }\end{array}$ \\
\hline Machine tool & $\begin{array}{l}\text { A machine spends energy related to the process itself, as well as to a series } \\
\text { of peripherals, dedicated to different aspects of the process-auxiliary processes } \\
\text { (coolant pumps, lubrication supply, technical air ventilation) }\end{array}$ & $\begin{array}{l}\text { Starting time } \\
\text { Downtime } \\
\text { Idle time } \\
\text { Basic time } \\
\text { Tool consumption } \\
\text { Cleaning }\end{array}$ \\
\hline System & $\begin{array}{l}\text { Related to the overall production line, including production and disposal of materials } \\
\text { and tools, and transport of materials/tools }\end{array}$ & $\begin{array}{l}\text { Production of raw material } \\
\text { Disposal/recycling of material } \\
\text { Production of tool } \\
\text { Disposal of tool } \\
\text { Production of consumables } \\
\text { Disposal of consumables } \\
\text { Transport }\end{array}$ \\
\hline
\end{tabular}

Table 1 Description of each level and listing of components included 
Table 2 Quantitative and qualitative parameters, divided with regards to their relation to raw material, machine tool, and electrical energy relation, but also in terms of manufacturing level

\begin{tabular}{|c|c|c|c|c|}
\hline & & $\begin{array}{l}\text { Raw material/final product-related } \\
\text { parameters }\end{array}$ & $\begin{array}{l}\text { Machine tool-related } \\
\text { parameters }\end{array}$ & $\begin{array}{l}\text { Electrical energy-related } \\
\text { parameters }\end{array}$ \\
\hline \multirow[t]{3}{*}{ Process level } & Qualitative & & & $C E F_{\text {elec }}$ \\
\hline & Quantitative & Raw material properties & Feed rate & Energy coefficients \\
\hline & & Final product properties & Process speed & \\
\hline \multirow[t]{2}{*}{ Machine tool level } & Qualitative & $C E F_{\text {material, } \text { cons }}$ & $\begin{array}{l}C E F_{\text {tool, cons }} \\
C E F_{i} \text { cons }\end{array}$ & $C E F_{\text {elec }}$ \\
\hline & Quantitative & $Q_{\text {material, cons }}$ & $\begin{array}{l}E_{\text {aux }} \\
E_{\text {tool, cons }}\end{array}$ & Energy coefficients \\
\hline \multirow[t]{2}{*}{ System level } & Qualitative & $\begin{array}{l}C E F_{\text {material, }} \text { cons } \\
C E F_{\text {material, transp }} \\
C E F_{\text {material, }} \text { prod } \\
C E F_{\text {material, disp }}\end{array}$ & $\begin{array}{l}C E F_{\text {tool, } \text { cons }} \\
C E F_{i, \text { cons }} \\
C E F_{i, \text { transp }} \\
C E F_{i, \text { prod }} \\
C E F_{i, \text { disp }}\end{array}$ & $C E F_{\text {elec }}$ \\
\hline & Quantitative & $\begin{array}{l}Q_{\text {material, }} \text { cons } \\
Q_{\text {material }, \text { transp }} \\
Q_{\text {material, }} \text { prod } \\
Q_{\text {material }, \text { disp }}\end{array}$ & $\begin{array}{l}E_{\text {aux }} \\
E_{\text {tool, cons }} \\
Q_{i, \text { cons }} \\
Q_{i, \text { transp }} \\
Q_{i, \text { prod }} \\
Q_{i, \text { disp }} \\
T_{i, \text { life }}\end{array}$ & Energy coefficients \\
\hline
\end{tabular}

(amount of energy, material and consumable), as seen in Table 2.

\subsection{Carbon emissions at system level}

At the system level, the carbon emissions are given by the sum of carbon emissions at machine level and carbon emissions from transport ( $\left.C E_{i, \text { transp }}\right)$, production $\left(C E_{i, \text { prod }}\right)$, and disposal $\left(C E_{i, \text { disp }}\right)$ of material, tools, and consumable:

$$
\begin{aligned}
C E_{\text {system }}= & C E_{\text {machine }} \\
& +\sum_{i}\left(C E_{i, \text { transp }}+C E_{i, \text { prod }}+C E_{i, \text { disp }}\right)
\end{aligned}
$$

Fig. 2 Description of levels, with raw material, machine tool, and energy as inputs and product and carbon footprint as outputs

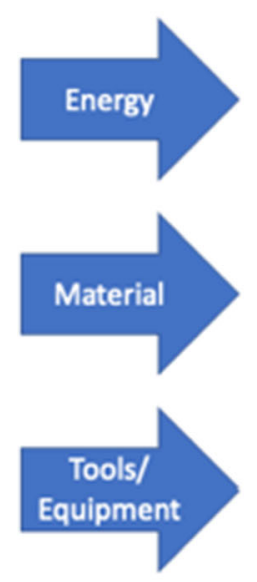

In details, carbon emissions of the overall production are calculated by:

$$
\begin{aligned}
& C E_{\text {system }}=C E F_{\text {elec }} \cdot E_{\text {process }}+C E F_{\text {elec }} \cdot E_{\text {aux }} \\
& +C E F_{\text {tool,cons }} \cdot E_{\text {tool,cons }}+\sum_{i} C E F_{i, \text { cons }} \cdot Q_{i, \text { cons }} \\
& +\sum_{i}\left[C E F_{i, \text { transp }} \cdot Q_{i, \text { transp }}+\left(C E F_{i, \text { prod }} \cdot Q_{i, \text { prod }}+C E F_{i, \text { disp }} \cdot Q_{i, \text { disp }}\right) \frac{t}{T_{i, \text { life }}}\right]
\end{aligned}
$$

where $C E F_{\text {elec }}$ is the carbon emission factor of electrical energy; $E_{\text {process }}$ energy required for the process itself; $E_{\text {aux }}$ energy required for the operation of auxiliary/peripheral equipment; $C E F_{\text {tool, cons }}$ carbon emission factor for tool 
consumption; $E_{\text {tool, cons }}$ energy required for tool consumption; $C E F_{i, \text { cons }}$ carbon emission factor for material and consumable consumption; $Q_{i}$, cons amount of material and consumable used in the operation; $C E F_{i, \text { transp }}$ carbon emission factor during transport to and from the production site; $Q_{i, \text { transp }}$ amount of transported quantity; $C E F_{i \text {, prod }}$ carbon emission factor of production of material, tool, and consumables; $Q_{i, \text { prod }}$ quantity produced; $C E F_{i, \text { disp }}$ carbon emission factor of disposal of material, tool, and consumables; $Q_{i}$, disp quantity that will be disposed or recycled; and $T_{i, \text { life }}$ lifetime of material, tool, and consumables.

\section{Sensitivity analysis}

\subsection{Material removal}

Using data from literature [16], a sensitivity analysis on turning of AISI4140 using carbide inserts in wet conditions was performed.

For the process level, energy consumed during turning is calculated based on the material removal volume $\left(V_{c}\right)$ and energy requirements $\left(k_{C}\right)$ :

$E_{c}=k_{C} \cdot V_{c}$

Carbon emissions due to electrical energy are given by the product of carbon emission factor for electrical energy $\left(C E F_{\text {elec }}\right)$ and the energy consumed for the turning $\left(E_{c}\right)$ :

$C E_{c}=C E F_{\text {elec }} \cdot E_{c}$

Energy is consumed when no turning takes place, but spindle is turning $\left(E_{\text {idle }}\right)$ and also during starting up $\left(E_{\text {basic }}\right)$ and shutting down ( $\left.E_{\text {downtime }}\right)$ of the machines, being in turn responsible for carbon emissions:

$$
\begin{aligned}
& C E_{\text {basic }}=C E F_{\text {elec }} \cdot E_{\text {basic }} \\
& C E_{\text {downtime }}=C E F_{\text {elec }} \cdot E_{\text {downtime }} \\
& C E_{\text {idle }}=C E F_{\text {elec }} \cdot E_{\text {idle }}
\end{aligned}
$$

During machine level, there are also the carbon emissions due to tool wear and consumption and due to tool mass $\left(M_{\text {tool }}\right)$ and tool lifetime $\left(T_{\text {life }}\right)$ :

$$
C E_{\text {tool, } \text { cons }}=C E F_{\text {tool, }, \text { cons }} \cdot M_{\text {tool }} \cdot \frac{t}{T_{\text {life }}}
$$

In addition, coolant consumption results in carbon emissions, based on the quantity of coolant consumed $\left(Q_{\text {cool }}\right)$ :

$C E_{\text {cool,cons }}=C E F_{\text {cool, cons }} \cdot Q_{\text {cool }} \cdot t$

At the system level, carbon emissions are related to the production and disposal of material, coolant, and waste. In this case, coolant disposal, material production, and material disposal are taken under consideration, based on the quantity produced $\left(Q_{\text {cool }}, \Delta m_{\text {material }}\right)$ or disposed $\left(M_{\text {chip }}\right)$ :

$C E_{\text {cool,disp }}=C E F_{\text {cool }, \text { disp }} \cdot Q_{\text {cool }} \cdot t$

$C E_{\text {material,prod }}=C E F_{\text {material,prod }} \cdot \Delta m_{\text {material }}$

$C E_{\text {chip }}=C E F_{\text {chip }, \text { isp }} \cdot M_{\text {chip }}$

Parameters in Equations (7)-(15) are characterized either as qualitative or quantitative, depending on whether they are linked to the way that power is generated, tool and coolant liquids are consumed, coolant and chips are disposed, and material is produced or linked to the quantity of energy, material, tool, and coolant consumed, produced, or disposed. Parameters are categorized in Table 3 , while sensitivity factors are summarized in Table 4.

The results from the sensitivity analysis are described in the following paragraphs, tables, and figures. In the case of carbon emission factor for electrical energy, the highest value is at the process level, showing that any change on the carbon emission factor for electrical energy will affect more the carbon emissions of process, much less the machine level with the least effect on the carbon emissions at the system level. Any variations of the rest of carbon emission factors will have no impact on the carbon emission at process level. Regarding the rest of carbon emission factors, machine level is affected by carbon emission factor of tool and coolant consumption, with the tool consumption being the second heaviest factor, with the strongest factor being the carbon emission factor for electrical energy. At the system level, the heaviest carbon emission factor is the one of material production, followed by the carbon emission factor of electrical energy and carbon emission factor of tool consumption. The impact of each carbon emission factor per level can be found in the sensitivity table (Table 4), and relevant plots are found in the Appendix 2.

Tornado plots are used in sensitivity analysis to show the impact of factors on the overall value. In Fig. 3, the only factor is the carbon emission factor of electrical energy, 
Table 3 Qualitative and quantitative parameters for carbon emission calculations, on each level (process, machine, and system) or factor (material, machine tool, electrical parameter)

\begin{tabular}{|c|c|c|c|c|}
\hline & & Raw material/product-related parameters & $\begin{array}{l}\text { Machine tool-related } \\
\text { parameters }\end{array}$ & $\begin{array}{l}\text { Electrical energy-related } \\
\text { parameters }\end{array}$ \\
\hline \multirow[t]{2}{*}{ Process level } & Qualitative & & & $C E F_{\text {elec }}$ \\
\hline & Quantitative & $M R R$ & $v_{C}, f$ & $k_{c}$ \\
\hline \multirow[t]{2}{*}{ Machine tool level } & Qualitative & & $\begin{array}{l}C E F_{\text {tool, }} \text { cons } \\
C E F_{\text {cool, cons }}\end{array}$ & $C E F_{\text {elec }}$ \\
\hline & Quantitative & $M R R$ & $\begin{array}{l}v_{C}, f, P_{\text {air }}, \\
P_{\text {downtime }}, P_{\text {basic }} \\
M_{\text {tool }}, T_{\text {life }}, \\
Q_{\text {cool }}, T_{\text {cool }},\end{array}$ & $k_{c}$ \\
\hline \multirow[t]{2}{*}{ System level } & Qualitative & $\begin{array}{l}C E F_{\text {material, }} \text { prod } \\
C E F_{\text {material, }} \text { disp }\end{array}$ & $C E F_{\text {cool, disp }}$ & $C E F_{\text {elec }}$ \\
\hline & Quantitative & $\begin{array}{l}\text { MRR } \\
M_{\text {chip }}\end{array}$ & $\begin{array}{l}v_{C}, f, P_{\text {air }}, \\
P_{\text {downtime }}, P_{\text {basic }} \\
M_{\text {tool }}, T_{\text {life }}, \\
Q_{\text {cool }}, T_{\text {cool }},\end{array}$ & $k_{c}$ \\
\hline
\end{tabular}

while in Fig. 4, three factors are affecting the carbon emissions, namely carbon emission factors for electrical energy, tool consumption, and coolant consumption. As seen in Fig. 4, the order of weight from heavier to lighter is carbon emission factor for electrical energy, carbon emission factor for tool consumption, and carbon emission factor for coolant consumption. In Fig. 5, the heaviest factor is the carbon emission factor of material production, followed by carbon emission factor of electrical energy. Carbon emission factors of tool consumption and chip disposal are also contributing to the carbon emissions at system level, with the weight of carbon emission factor of coolant disposal and coolant consumption being so negligible that are close to zero on Fig. 5.

\subsection{Primary forming}

To perform the sensitivity analysis for a primary forming process, the example from Liu et al. [20] was used, which was based on the casting of box-beams from base sand, dry clay, and water.
For the process level, energy was consumed during the pressing of the sand-clay-water mixture and the carbon footprint is given by:

$C E_{\text {comp }}=\frac{P_{\text {comp }}}{W_{\text {comp }}} \cdot C E F_{\text {ele }}$

which was calculated based on the power of machine for the compression $\left(P_{\text {comp }}\right)$, rate of compression $\left(W_{\text {comp }}\right)$, and carbon emission factor of electrical energy $\left(C E F_{\text {ele }}\right)$.

Electrical energy is consumed in other auxiliary process, such as mold drying $\left(C E_{d r y}\right)$, shake out $\left(C E_{s h a}\right)$, and cleaning $\left(C E_{c l e}\right)$. Carbon emissions of the auxiliary processes are given by:

$$
\begin{gathered}
C E_{\text {dry }}=\left[U_{\text {san }}^{\text {dry }} \cdot M_{\text {san }}\left(1-\eta_{\text {water }}\right) \Delta T\right] C E F_{\text {ele }} \\
+\left(U_{\text {water }} \cdot \Delta T_{\text {water }}+Q\right) M_{\text {san }} \eta_{\text {water }} C E F_{\text {ele }} \\
C E_{\text {sha }}=P_{\text {sha }} \cdot \frac{M_{\text {san }}}{} \\
W_{\text {sha }} C E F_{\text {ele }} \quad C E_{\text {cle }}=P_{\text {cle }} \cdot \frac{A_{\text {cas }}}{}
\end{gathered}
$$

\begin{tabular}{|c|c|c|c|c|c|c|}
\hline \multirow{2}{*}{$\frac{\text { Carbon emission factor }}{C E F_{\text {elec }}}$} & \multicolumn{2}{|c|}{ Process } & \multicolumn{2}{|l|}{ Machine } & \multicolumn{2}{|l|}{ System } \\
\hline & $E_{\text {elec }}$ & 1 & $E_{\text {elec }}+E_{\text {air }}+E_{\text {downtime }}+E_{\text {basic }}$ & 0.668 & $E_{\text {elec }}+E_{\text {air }}+E_{\text {downtime }}+E_{\text {basic }}$ & 0.0585 \\
\hline$C E F_{\text {tool, } \text { cons }}$ & & 0 & $Q_{\text {tool }} \frac{t}{T_{\text {life }}}$ & 0.3262 & $Q_{\text {tool }} \frac{t}{T_{\text {life }}}$ & 0.0286 \\
\hline$C E F_{\text {cool, } \text { cons }}$ & & 0 & $Q_{\text {cool }} t_{c}$ & 0.0058 & $Q_{\text {cool }} t_{c}$ & 0.0005 \\
\hline$C E F_{\text {cool, disp }}$ & & 0 & & 0 & $V_{\text {cool, disp }}$ & $4 * 10^{-5}$ \\
\hline$C E F_{\text {mat, prod }}$ & & 0 & & 0 & $\Delta m_{\text {material }}$ & 0.9051 \\
\hline$C E F_{\text {chip }}$ & & 0 & $M_{\text {chip }}$ & 0 & $M_{\text {chip }}$ & 0.0073 \\
\hline
\end{tabular}

Table 4 Sensitivity coefficients from the sensitivity analysis 
Fig. 3 Tornado plot for material removal at process level.

Equation (7) was used for this plot $\left(C E_{c}=C E F_{\text {elec }} \cdot E_{c}\right)$, with amount of energy consumed during turning $\left(E_{c}\right)$ remaining constant, while carbon emission factor ranging from 0.39 to 1.17 $\mathrm{kgCO}_{2} / \mathrm{kWh}$. The rest of the carbon emission factors are not involved at process level; hence, they do not have impact on the carbon emissions at process level

\section{Tornado plot for Material Removal at Process} Level

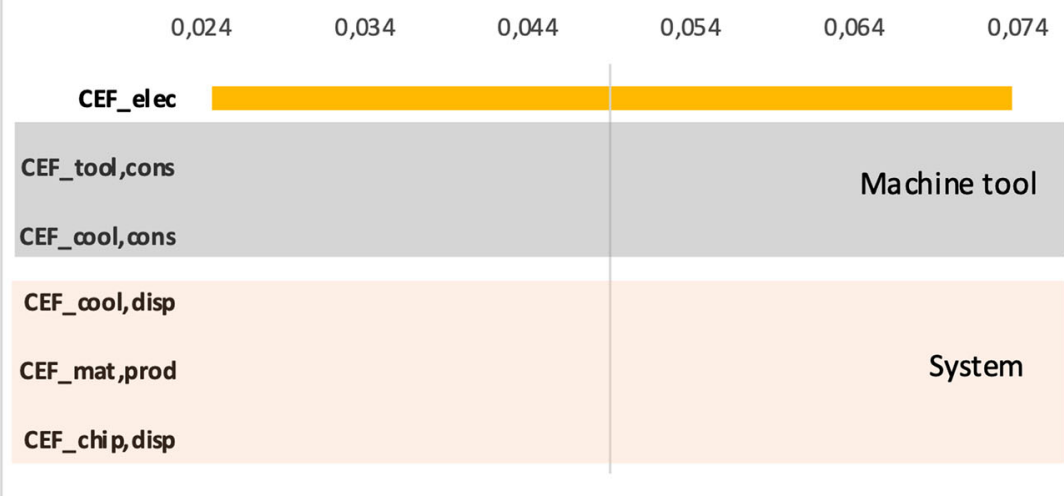

$W_{\text {cle }} C E F_{\text {ele }}$ where $U_{\text {san }}^{d r y}$ is the specific heat capacity of dried clay sand, $M_{\text {san }}$ mass of casting sand, $\eta_{\text {water }}$ fraction of water, $U_{\text {water }}$ specific heat capacity of water, $\Delta T_{\text {water }}$ the difference between water's boiling point and its initial temperature, $Q$ evaporation heat, $P_{\text {sha }}$ power of the shakeout machine and $W_{\text {sha }}$ shakeout rate, $P_{\text {cle }}$ power of cleaning machine, $A_{\text {cas }}$ surface area of casting, and $W_{\text {cle }}$ cleaning rate.

At the system level, carbon emissions come from the sand production $\left(C E_{n e w}\right)$, sand reclamation $\left(C E_{r e c}\right)$, and sand mixing $\left(C E_{m i x}\right)$ :

$$
\begin{aligned}
& C E_{\text {new }}=\left(\eta_{\text {new }} \cdot M_{\text {san }}\right) c e_{\text {rec }} \\
& c e_{\text {new }}=\eta_{\text {cla }} \cdot\left(E_{\text {gas }}^{c l a} \cdot C E F_{\text {gas }}+E_{c o a}^{c l a} \cdot C E F_{\text {coa }}+E_{c r u}^{c l a} \cdot C E F_{c r u}+E_{\text {die }}^{c l a} \cdot C E F_{\text {die }}+E_{\text {ele }}^{c l a} \cdot C E F_{\text {ele }}\right) \\
& +\eta_{\text {san }} \cdot\left(E_{\text {gas }}^{\mathrm{san}} \cdot C E F_{\text {gas }}+E_{\text {coa }}^{\mathrm{san}} \cdot C E F_{\text {coa }}+E_{\text {cru }}^{\mathrm{san}} \cdot C E F_{\text {cru }}+E_{\text {die }}^{\mathrm{san}} \cdot C E F_{\text {die }}+E_{\text {ele }}^{\mathrm{san}} \cdot C E F_{\text {ele }}\right)
\end{aligned}
$$$$
C E_{\text {rec }}=\frac{\eta_{\text {rec }} \cdot M_{\text {san }}}{W_{\text {rec }}} \cdot P_{\text {rec }} \cdot C E F_{\text {ele }}
$$$$
C E_{\text {mix }}=\frac{\eta_{\text {rec }} \cdot M_{\text {san }}}{W_{\text {rec }}} \cdot P_{\text {rec }} \cdot C E F_{\text {ele }}
$$

where $\eta_{\text {new }}$ is the mass fraction of new sand and $M_{\text {san }}$ mass of casting sand; $E_{\text {gas }}^{\text {cla }}, E_{\text {coa }}^{\text {cla }}, E_{c r u}^{c l a}, E_{\text {die }}^{\text {cla }}$, and $E_{\text {ele }}^{\text {cla }}$ energy consumptions from clay and $E_{\text {gas }}^{\text {san }}, E_{\text {coa }}^{\text {san }}, E_{c r u}^{\text {san }}, E_{\text {die }}^{\text {san }}$, and $E_{\text {ele }}^{\text {san }}$ energy consumptions from sand; $W_{\text {rec }}$ reclamation rate and $P_{\text {rec }}$ power of reclamation; and $W_{m i x}$ the mixing rate and $P_{\text {mix }}$ power of mixing equipment.

Finally, the carbon emissions due to transport of raw material from a distance of $271.07 \mathrm{~km}$ (average distance in China) were calculated by:

$$
C E_{\text {transp }}=\left(C E F_{\text {ele }} \cdot E_{\text {elec,transp }}+C E F_{\text {coa }} \cdot E_{\text {coa,transp }}+C E F_{\text {die }} \cdot E_{\text {die,transp }}\right) \cdot d
$$

Parameters in the carbon emission calculation can be divided per process, machine, and system level, while the parameters are related to electrical energy-, machine-, and material-related parameters. In each group, the parameters are either qualitative, in terms of footprint, or quantitative, in terms of how much energy or power or material is used (Table 5).

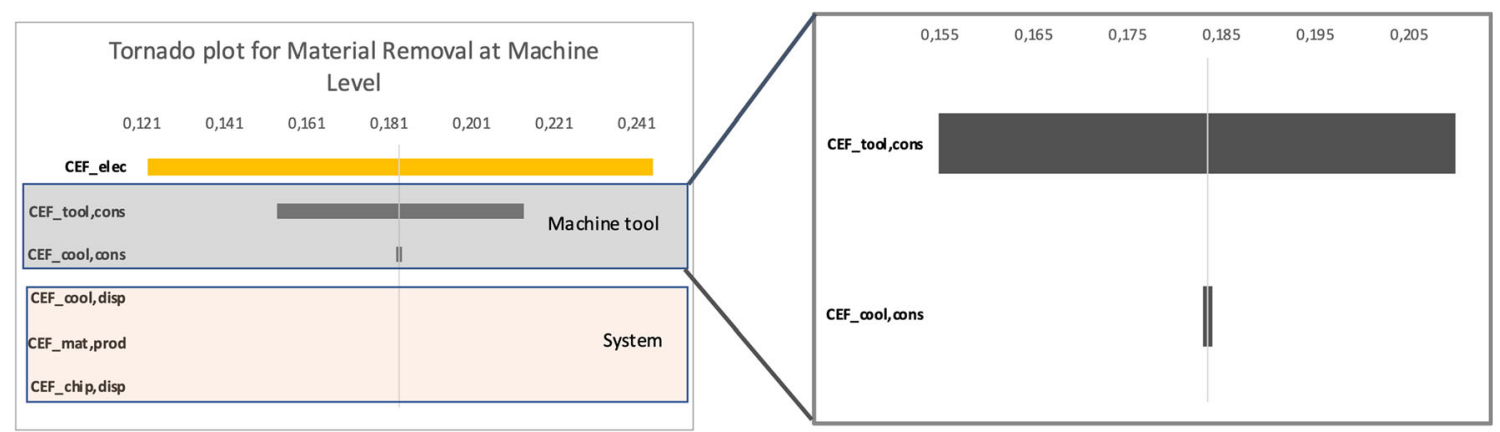

Fig. 4 Tornado plot for material removal at machine level (left), with zooming into the carbon emission factors of tool and coolant consumption at machine level (right). Equations (8)-(12) were used for this plot, with only carbon emission factors ranging, while the rest parameters remaining the same. The carbon emission factor for electrical energy $\left(C E F_{\text {elec }}\right)$ still is the heaviest contributing factor, followed by carbon emission factor of tool consumption $\left(C E F_{\text {tool, cons }}\right)$ and carbon emission factor of coolant consumption $\left(C E F_{\text {cool, cons }}\right)$ 


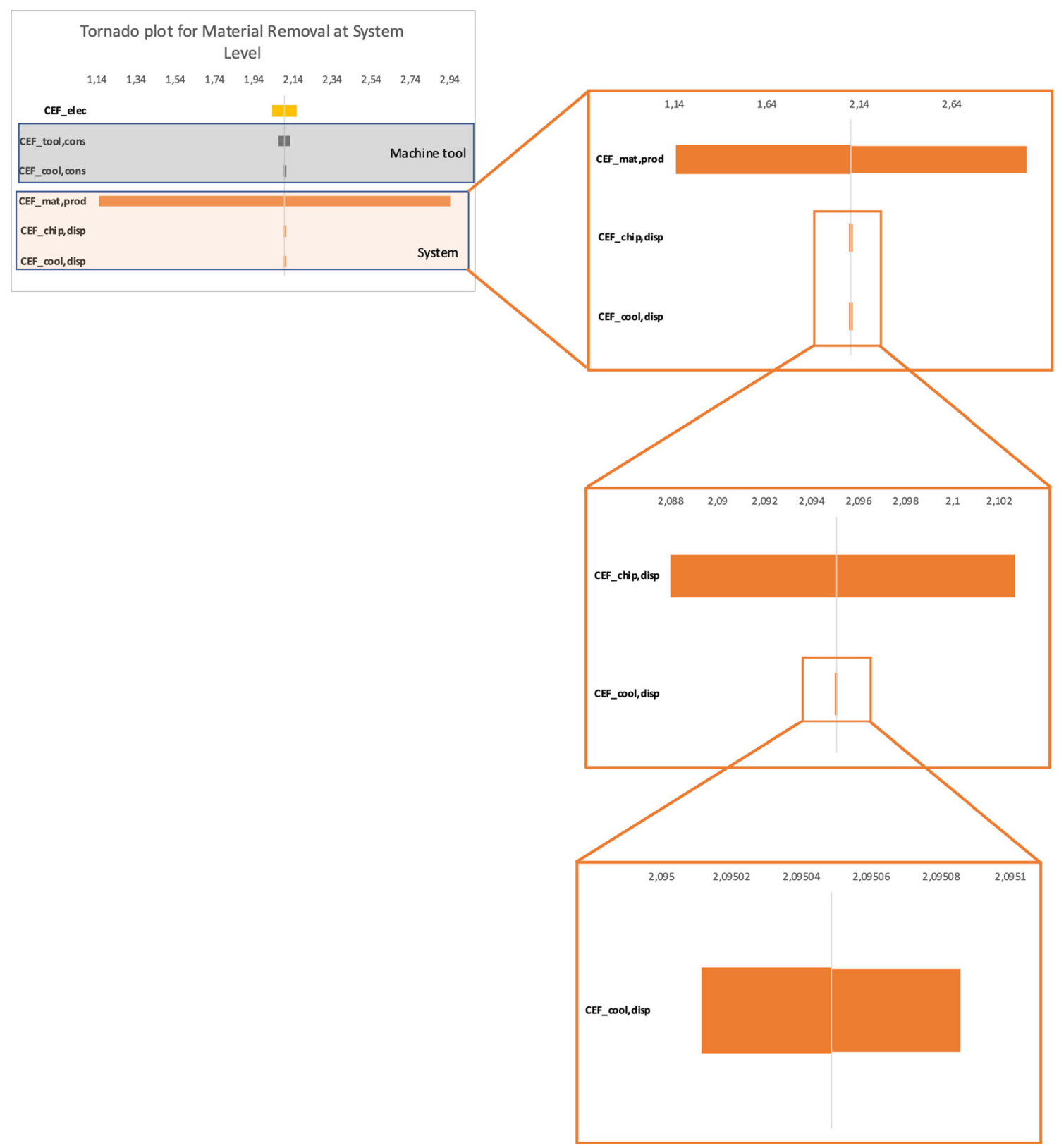

Fig. 5 Tornado plot for material removal at system level (left), zooming into the carbon emission factors from heaviest contributing factor $\left(C E F_{\text {material, }}\right.$ prod $)$ to the lightest contributing factor $\left(C E F_{\text {cool, disp }}\right)$.

The results from the sensitivity analysis can be found in the following table and figures. The values from sensitivity analysis can be found in Table 6 (with relevant spider charts in Appendix 2).

Tornado charts were plotted using the sensitivity factors and their effect on carbon emissions at process, machine, and system levels. As seen in Fig. 6, the only contributing factor is carbon emission factor for electrical energy and so is in Fig. 7. Regarding system level, the heaviest contributing factor is the carbon emission factor of coal
Equations (13)-(15) were used. Overall, the heaviest contributing factor is the carbon emission factor for material production, followed by the carbon emission factor for electrical energy

consumption, followed by the carbon emission factor for electrical energy and carbon emission factor for diesel consumption (Fig. 8). The carbon emissions factor of crude oil and gas consumption has negligible effect on carbon emissions at system level.

\subsection{Deforming}

The sensitivity analysis for a deforming process was performed for the incremental forming of roll-bonded 
Table 5 Qualitative and quantitative parameters, related to electrical energy, machine, and material, in all levels of production (process, machine, system)

\begin{tabular}{|c|c|c|c|c|}
\hline & & Material-related parameters & Machine tool-related parameters & Electrical energy-related parameters \\
\hline \multirow[t]{2}{*}{ Process level } & Qualitative & & & $C E F_{\text {elec }}$ \\
\hline & Quantitative & & $P_{\text {comp }}, W_{\text {comp }}$ & \\
\hline \multirow[t]{2}{*}{ Machine tool level } & Qualitative & & & $C E F_{\text {elec }}$ \\
\hline & Quantitative & $M_{\text {san }}, A_{\text {cas }}$ & $\begin{array}{l}U_{\text {san }}^{\text {dry }}, \eta_{\text {water }}, U_{\text {water }}, Q \\
P_{\text {comp }}, W_{\text {comp }}, \Delta T_{\text {water }} \\
P_{\text {sha }}, W_{\text {sha }} \\
P_{\text {cle }}, W_{\text {cle }}\end{array}$ & \\
\hline \multirow[t]{2}{*}{ System level } & Qualitative & $\eta_{c l a}, \eta_{\text {san }}$ & $\begin{array}{l}C E F_{\text {coa }}, C E F_{c r u} \\
C E F_{d i e}\end{array}$ & $C E F_{\text {elec },} C E F_{\text {gas }}$ \\
\hline & Quantitative & $\begin{array}{l}M_{\text {san }}, A_{\text {cas }} \\
\eta_{\text {new }}, M_{\text {san }} \\
\eta_{\text {rec }}\end{array}$ & $\begin{array}{l}P_{\text {comp }}, W_{\text {comp }}, \Delta T_{\text {water }} \\
P_{\text {sha }}, W_{\text {sha }}, \Delta T \\
P_{\text {cle }}, W_{\text {cle }} \\
P_{\text {rec }}, W_{\text {rec }} \\
P_{\text {mix }}, W_{\text {mix }} \\
U_{\text {san }}^{\text {dry }}, \eta_{\text {water }}, U_{\text {water }}, Q \\
M_{\text {gas }}^{\text {cla }}, M_{\text {caa }}^{\text {cla }}, M_{\text {cru }}^{\text {cla }} \\
M_{\text {die }}^{\text {cla }}, M_{\text {gas }}^{\text {san }}, M_{\text {coa }}^{\text {san }} \\
M_{\text {cru }}^{\text {san }}, M_{\text {die }}^{\text {san }}\end{array}$ & $M_{\text {ele }}^{\text {cla }}, M_{\text {ele }}^{\text {san }}$ \\
\hline
\end{tabular}

$\mathrm{Cu} / \mathrm{Steel}$ laminates from Al-Ghamdi and Hussain work [85].

The process was the pressing of the laminates with energy required given by:

$E_{\text {pres }}=\frac{W}{\eta_{\text {Pres }}}$

$W$ is the deforming work and $\eta_{\text {Pres }}$ efficiency of hydraulic press.

The carbon emissions of the process level are given by:

$C E_{\text {pres }}=E_{\text {pres }} \cdot C E F_{\text {elec }}$
At the machine level, carbon dioxide is also emitted during lubricant consumption $\left(C E_{\text {lub }, \text { cons }}\right)$, tool consumption $\left(C E_{\text {tool }}\right.$, cons $)$, fixture consumption $\left(C E_{f i x}\right.$, cons $)$, annealing $\left(C E_{\text {anneal }}\right)$, bonding $\left(C E_{\text {bond }}\right)$, and cutting of the sheets:

$$
\begin{aligned}
& C E_{\text {lub,cons }}=t_{f} \cdot C E F_{\text {lub,cons }} \\
& C E_{\text {tool,cons }}=\frac{t_{f}}{T_{\text {formingtool }}} \cdot M_{\text {tool }} \cdot C E F_{\text {tool,cons }} \\
& C E_{\text {fix,cons }}=\frac{t_{f}}{T_{\text {fixtures }}} \cdot C E F_{\text {fix,cons }} \\
& C E_{\text {anneal }}=E_{\text {anneal }} \cdot C E F_{\text {elec }}
\end{aligned}
$$

\begin{tabular}{|c|c|c|c|c|c|c|}
\hline $\begin{array}{l}\text { Carbon } \\
\text { emission } \\
\text { factor }\end{array}$ & Process & & Machine & & System & \\
\hline$C E F_{\text {elec }}$ & $\underline{P_{\text {comp }}}$ & & $W_{\text {comp }}$ & 1 & 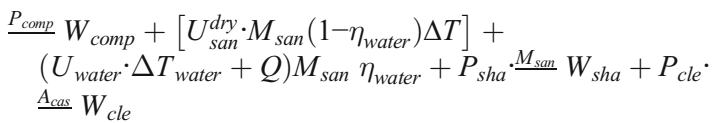 & 1 \\
\hline$\underline{P_{\text {comp }}}$ & & & {$\left[U_{\text {san }}^{d r y} \cdot M_{\text {san }}\left(1-\eta_{\text {water }}\right) \Delta T\right]+$} & & 0.357 & \\
\hline$W_{\text {comp }}$ & & & $\left(U_{\text {water }} \cdot \Delta T_{\text {water }}+Q\right) M_{\text {san }} \eta_{\text {water }}+P_{\text {sha }} \cdot \frac{M_{\text {san }}}{2}$ & & & \\
\hline+ & & & $\begin{array}{l}W_{\text {sha }}+P_{\text {cle }} \cdot \frac{A_{\text {cas }}}{W_{\text {cle }}}+\frac{\eta_{\text {rec }} \cdot M_{\text {san }}}{W_{\text {rec }}} \cdot P_{\text {rec }} \\
+E_{\text {elec transp }} \cdot d\end{array}$ & & & \\
\hline$C E F_{\text {gas }}$ & & 0 & & 0 & $\eta_{\text {new }} \cdot M_{\text {san }}\left(\eta_{\text {cla }} E_{\text {gas }}^{\text {cla }}+\eta_{\text {san }} E_{\text {gas }}^{\text {san }}\right)$ & $6 * 10^{-9}$ \\
\hline$C E F_{c o a}$ & & 0 & & 0 & $\eta_{\text {new }} \cdot M_{\text {san }}\left(\eta_{\text {cla }} E_{\text {gas }}^{\text {cla }}+\eta_{\text {san }} E_{\text {gas }}^{\text {san }}\right)+E_{\text {coa }, \text { transp }} \cdot d$ & 0.4849 \\
\hline$C E F_{c r u}$ & & 0 & & 0 & $\eta_{\text {new }} \cdot M_{\text {san }}\left(\eta_{\text {cla }} E_{\text {gas }}^{\text {cla }}+\eta_{\text {san }} E_{\text {gas }}^{\text {san }}\right)$ & $10^{-7}$ \\
\hline$C E F_{\text {die }}$ & & 0 & & 0 & $\eta_{\text {new }} \cdot M_{\text {san }}\left(\eta_{\text {cla }} E_{\text {die }}^{\text {cla }}+\eta_{\text {san }} E_{\text {die }}^{\text {san }}\right)+E_{\text {die, transp }} \cdot d$ & 0.1582 \\
\hline
\end{tabular}

Table 6 Sensitivity coefficients from the sensitivity analysis 
Fig. 6 Tornado plot for primary forming at process level. The main contributing factor is carbon emission factor for electrical energy $\left(C E F_{\text {ele }}\right)$ as determined by Equations 16. The rest of the carbon emission factors are at system level

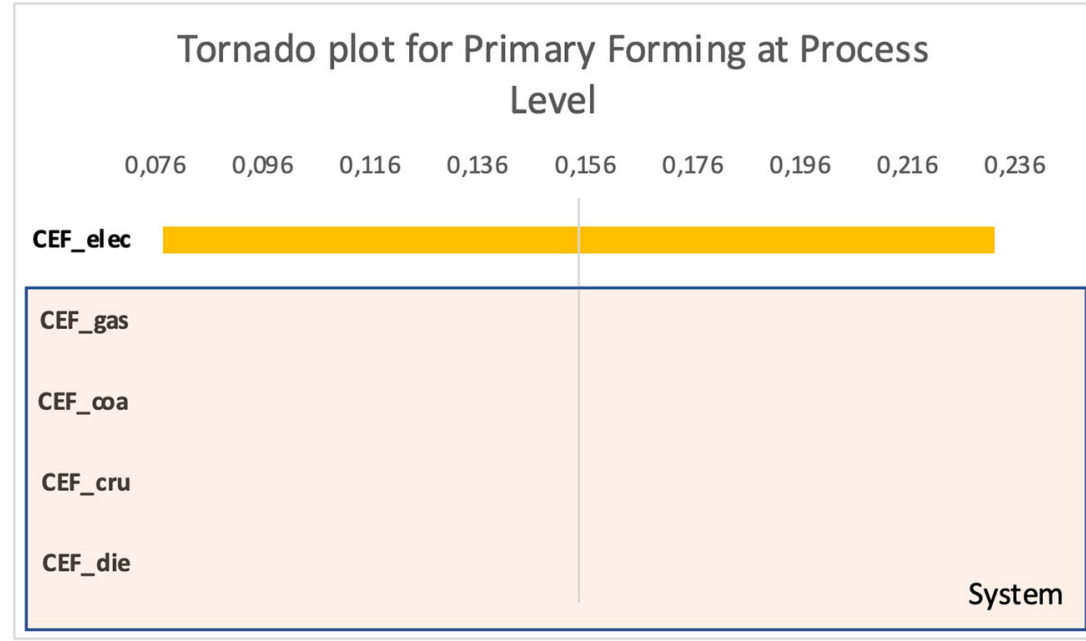

$$
\begin{aligned}
& C E_{\text {bond }}=E_{\text {bond }} \cdot C E F_{\text {elec }} \\
& C E_{\text {cut }}=E_{\text {cut }} \cdot C E F_{\text {elec }}
\end{aligned}
$$

where $t_{f}$ is the time required for forming, $C E F_{l u b \text {, cons }}$ carbon emission factor for lubricant consumption, $T_{\text {formingtool }}$ lifetime of forming tool, $M_{\text {tool }}$ mass of tool, $C E F_{\text {tool, cons }}$ carbon emission factor for tool consumption., $T_{\text {fixtures }}$ lifetime of fixtures, $C E F_{f i x}$, cons carbon emission factor for fixture usage, $E_{\text {anneal }}$ energy consumption during annealing, $E_{\text {bond }}$ energy consumption during bonding, and $E_{c u t}$ energy required for cutting of the sheets.

At the level of the system, the additional carbon emissions are given by the production of material $\left(C E_{\text {mat, prod }}\right)$ and synthetic lubricant $\left(C E_{\text {lubr, prod }}\right)$ :

$$
C E_{\text {mat,prod }}=M_{C u} \cdot C E F_{C u, p r o d}+M_{\text {Steel }} \cdot C E F_{\text {Steel,prod }}
$$

$C E_{\text {lubr,prod }}=V_{\text {lubr }} \cdot C E F_{\text {lubr,prod }}$

where $M_{C u}$ is the mass of $\mathrm{Cu}$ used for the sheet, $C E F_{C u}$, prod carbon emission factor for the production of $\mathrm{Cu}, M_{\text {Steel }}$ mass of Steel used for the sheet, $C E F_{\text {Steel, prod }}$ carbon emission factor for the production of Steel, $V_{l u b r}$ volume of lubricant used during incremental forming, and $C E F_{\text {lubr, prod }}$ carbon emission factor for the production of lubricant.

Similarly, the parameters are grouped with regards to their link to electrical energy, machine, or material, in the level of carbon emission calculation (process, machine, system level). Each group is divided into qualitative (in terms of footprint) and quantitative (use of less energy, resources, and material) (Table 7).

Sensitivity analysis was performed, and the results are the following. The sensitivity factors can be found in the relevant table (Table 8, with relevant spider charts in Figs. 12, 13, 14 in
Fig. 7 Tornado plot for primary forming at machine level. The main contributing factor is carbon emission factor for electrical energy $\left(C E F_{\text {ele }}\right)$ as determined by Equations $16-19$. The rest of the carbon emission factors are at system level

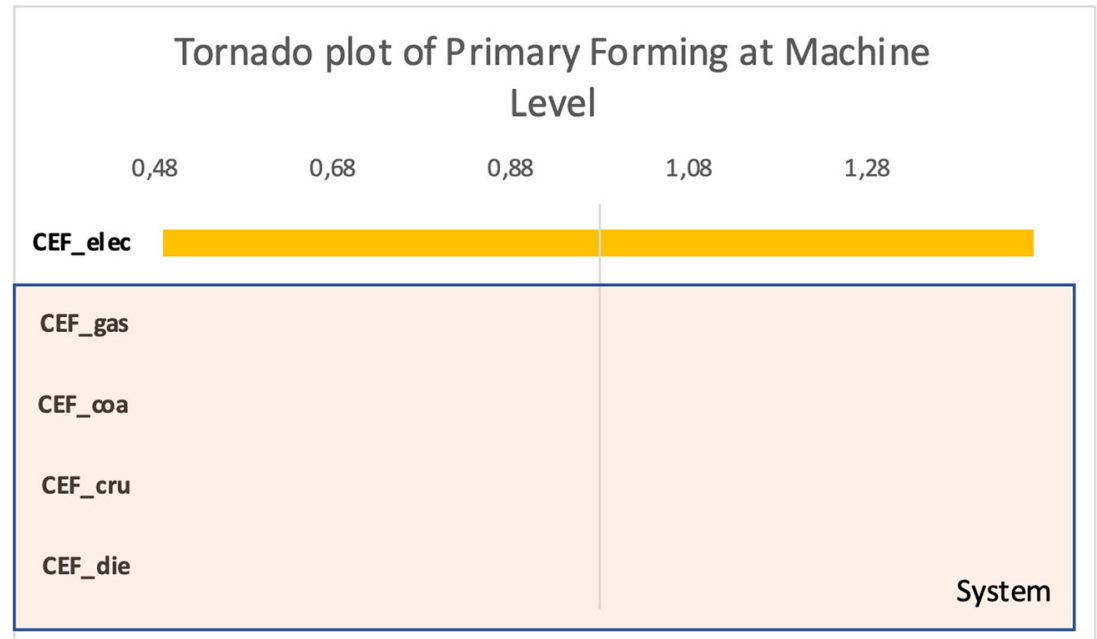




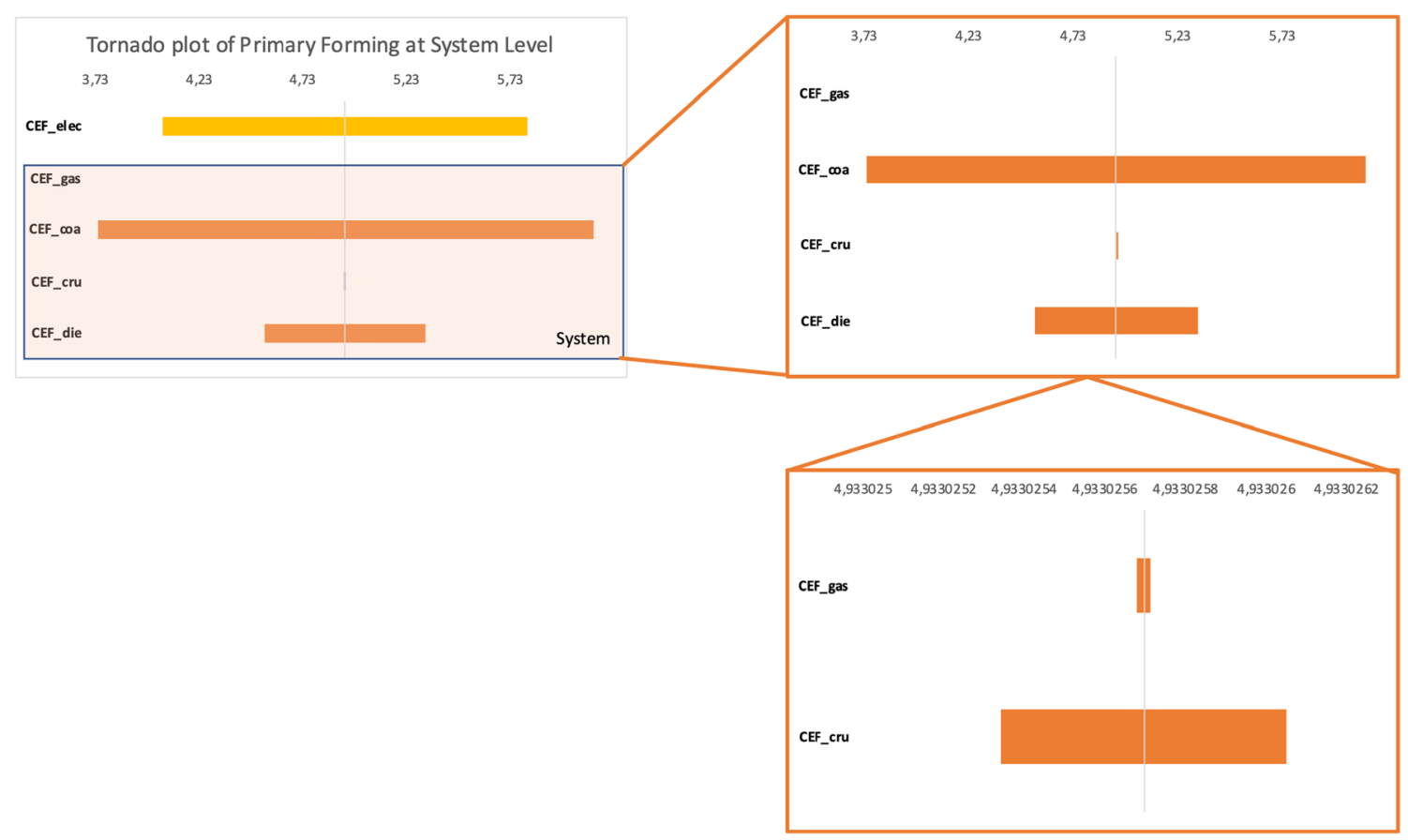

Fig. 8 Tornado plot for primary forming at system level (left), with zooming into the system level (top right and bottom right). The heaviest contributing factors are carbon emission factor of coal or carbon emission

Appendix 2), showing that the strongest contributing factor at all levels is the carbon emission factor for electrical energy. Carbon emission factors of material production are also strong contributors at system level but not in the same degree as other processes because this specific process has some energyintensive steps, such as annealing with duration of $2 \mathrm{~h}$. The contribution of the rest of the carbon emission actors is negligible $(<0.02)$.

Tornado charts from the sensitivity analysis confirm that the strongest contributing factor at all levels is the carbon emission factor of electrical energy consumption factor of diesel (top right), and the lightest contributing factors are carbon emission factor of gas or carbon emission factor of crude oil (bottom right). Equations 20-24 were used for this plot

(Figs. 9 and 11). At process level, as in both the previous examples, the only factor is the carbon emission factor of electrical energy (Fig. 9), while at machine level, there is a considerably small contribution from the carbon emission factor of the lubricant consumption during the deforming (Fig. 10). At system level, the second contributing factor is the carbon emission factor for steel production, closely followed by the carbon emission factor for $\mathrm{Cu}$ production (Fig. 11). The lightest contributing factor comes from the carbon emission factor of lubricant production.

Table 7 Qualitative and quantitative parameters, related to electrical energy, machine, and material, in all levels of production (process, machine, system)

\begin{tabular}{|c|c|c|c|c|}
\hline & & Material-related parameters & Machine-related parameters & Electrical energy-related parameters \\
\hline Process level & $\begin{array}{l}\text { Qualitative } \\
\text { Quantitative }\end{array}$ & $E_{\text {pres }}$ & $E_{\text {pres }}$ & $C E F_{\text {elec }}$ \\
\hline Machine level & $\begin{array}{l}\text { Qualitative } \\
\text { Quantitative }\end{array}$ & $E_{\text {pres }}$ & $\begin{array}{l}C E F_{\text {lub }, \text { cons }}, C E F_{\text {tool, cons }} \\
C E F_{\text {fix }}, \text { cons } \\
E_{\text {pres }}, t_{f}, T_{\text {formingtool }} \\
T_{\text {fixtures }}\end{array}$ & $\begin{array}{l}C E F_{\text {elec }} \\
E_{\text {anneal }}, E_{\text {bond }} \\
E_{\text {cut }}\end{array}$ \\
\hline System level & $\begin{array}{l}\text { Qualitative } \\
\text { Quantitative }\end{array}$ & $\begin{array}{l}C E F_{C u, \text { prod }} \\
C E F_{\text {Steel, prod }} \\
E_{\text {pres }}, M_{\text {Steel }}, M_{C u}\end{array}$ & $\begin{array}{l}C E F_{\text {lub }, \text { cons }}, C E F_{\text {tool }, \text { cons }} \\
C E F_{\text {fix }}, \text { cons } \\
V_{\text {lubr }}, t_{f}, T_{\text {formingtool }} \\
T_{\text {fixtures }}, E_{\text {pres }}\end{array}$ & $C E F_{\text {elec }}$ \\
\hline
\end{tabular}


Table 8 Sensitivity coefficients from the sensitivity analysis

\begin{tabular}{|c|c|c|c|c|c|c|}
\hline \multirow{2}{*}{$\frac{\text { Carbon emission factor }}{\boldsymbol{C E}_{\text {elec }}}$} & \multicolumn{2}{|c|}{ Process } & \multicolumn{2}{|l|}{ Machine } & \multicolumn{2}{|l|}{ System } \\
\hline & $E_{\text {pres }}$ & 1 & $E_{\text {pres }}+E_{\text {anneal }}+E_{\text {bond }}+E_{\text {bond }}+E_{\text {cut }}$ & 0.981 & $E_{\text {pres }}+E_{\text {anneal }}+E_{\text {bond }}+E_{\text {bond }}+E_{\text {cut }}$ & 0.6445 \\
\hline$C E F_{l u b, c o n s}$ & & 0 & $t_{f}$ & 0.0179 & $t_{f}$ & 0.0118 \\
\hline$C E F_{\text {tool,cons }}$ & & 0 & $\stackrel{t_{f}}{-} T_{\text {formingtool }}$ & 0.0001 & $t_{f} T_{\text {formingtool }}$ & $7 * 10^{-5}$ \\
\hline$C E F_{f i x, c o n s}$ & & 0 & ${ }^{t_{f}} T_{\text {fixtures }}$ & 0.0009 & $\underline{t}_{f} T_{\text {fixtures }}$ & 0.0006 \\
\hline$C E F_{C u, p r o d}$ & & 0 & & & $M_{C u}$ & 0.1415 \\
\hline$C E F_{\text {Steel,prod }}$ & & & & & $M_{\text {Steel }}$ & 0.1665 \\
\hline$C E F_{\text {lubr,prod }}$ & & & & & $V_{l u b r}$ & 0.035 \\
\hline
\end{tabular}

\section{Discussion}

Carbon emissions in manufacturing are generated from consumption of electrical energy at process, machine (mainly by auxiliary equipment), and system level; consumption of tools and coolant liquids; production and disposal of material, tools, and liquids; and transportation of materials in general. From the analysis presented earlier (Sections 3 and 4), there are two main types of carbon emissions: (a) related to consumption of electrical energy and (b) related to production, disposal, or transportation of raw materials, tools, and fluids. From the sensitivity analysis in all three examples, the common source of carbon emissions is the electrical energy at process and machine levels. At system level, the situation is more complex and is highly dependent on the example. But even in these cases, the carbon emissions related to the electrical energy are one of the strongest contributing factors for the total carbon emissions at system level.
Most studies on carbon emission calculation are using a simplistic approach of reducing the energy consumption via optimization of the process parameters, without weighing the importance of other sources of carbon emissions or without reducing the carbon emission factor for electrical energy. In details, the majority of the papers list the energy requirements of the process and the auxiliary equipment for a specific process and then multiply the result with the carbon emission factor for the electrical energy. For the rest of the carbon emissions that are not directly involved with the consumption of electrical energy, equations related to the consumption of resources are used. In general, the focus is primarily on the reduction of the electrical energy consumption, followed by the optimization of the use of resources. Despite the popularity of this approach, it fails to either result in significant carbon footprint reduction or to identify which parts of the process will result in the highest reduction of carbon emissions. The latter is extremely important since the carbon emissions from the production of raw materials can be significantly larger than
Fig. 9 Tornado plot for deforming at process level. Equation (26) $\left(C E_{\text {pres }}=E_{\text {pres }}\right.$. $\left.C E F_{\text {elec }}\right)$ was used at process level, with only contributing factor being the carbon emission factor for electrical energy

\begin{tabular}{|c|c|c|c|c|c|c|c|c|}
\hline \multicolumn{9}{|c|}{ Tornado plot for Deforming at Process Level } \\
\hline 0,2 & 0,25 & 0,3 & 0,35 & 0,4 & 0,45 & 0,5 & 0,55 & 0,6 \\
\hline \multicolumn{9}{|l|}{ CEF_elec } \\
\hline \multicolumn{9}{|l|}{ CEF_lubr,cons } \\
\hline \multicolumn{9}{|l|}{ CEF_tool,cons } \\
\hline CEF_fix,cons & & & & & & \multicolumn{3}{|c|}{ Machine tool } \\
\hline \multicolumn{9}{|l|}{ CEF_Cu, prod } \\
\hline \multicolumn{9}{|l|}{ CEF_Steel, prod } \\
\hline CEF_lubr,prod & & & & & & & & System \\
\hline
\end{tabular}




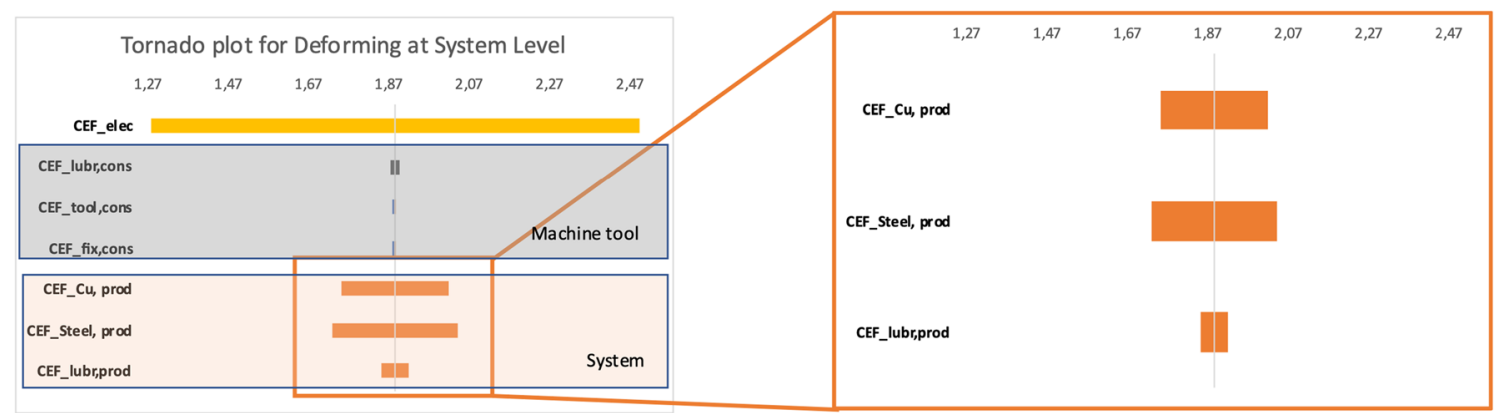

Fig. 11 Tornado plot for deforming at system level (left), with zooming into the system level part (right). Overall, at system level, the heaviest contributing factor is the carbon emission factor of electrical energy, followed by carbon emission factor of steel production, carbon emission factor of $\mathrm{Cu}$ production, and carbon emission factor of lubricant production (right). The impact of carbon emissions of the machine tool level (e.g., lubricant consumption, tool consumption, and fixture consumption) is negligible

factor weighs the more at each manufacturing level, and they could potentially choose to reduce or optimize the component that bares the least significance on the overall carbon footprint.

Alternatively, a proper approach should first define the heaviest contributing steps and then should follow one the following ways to reduce carbon emission factors: (1) by reducing the carbon emission factors, (2) by improving the energy efficiency of the process, (3) by better planning the design of the product, and (4) by using less carbon-intensive tools and consumables.

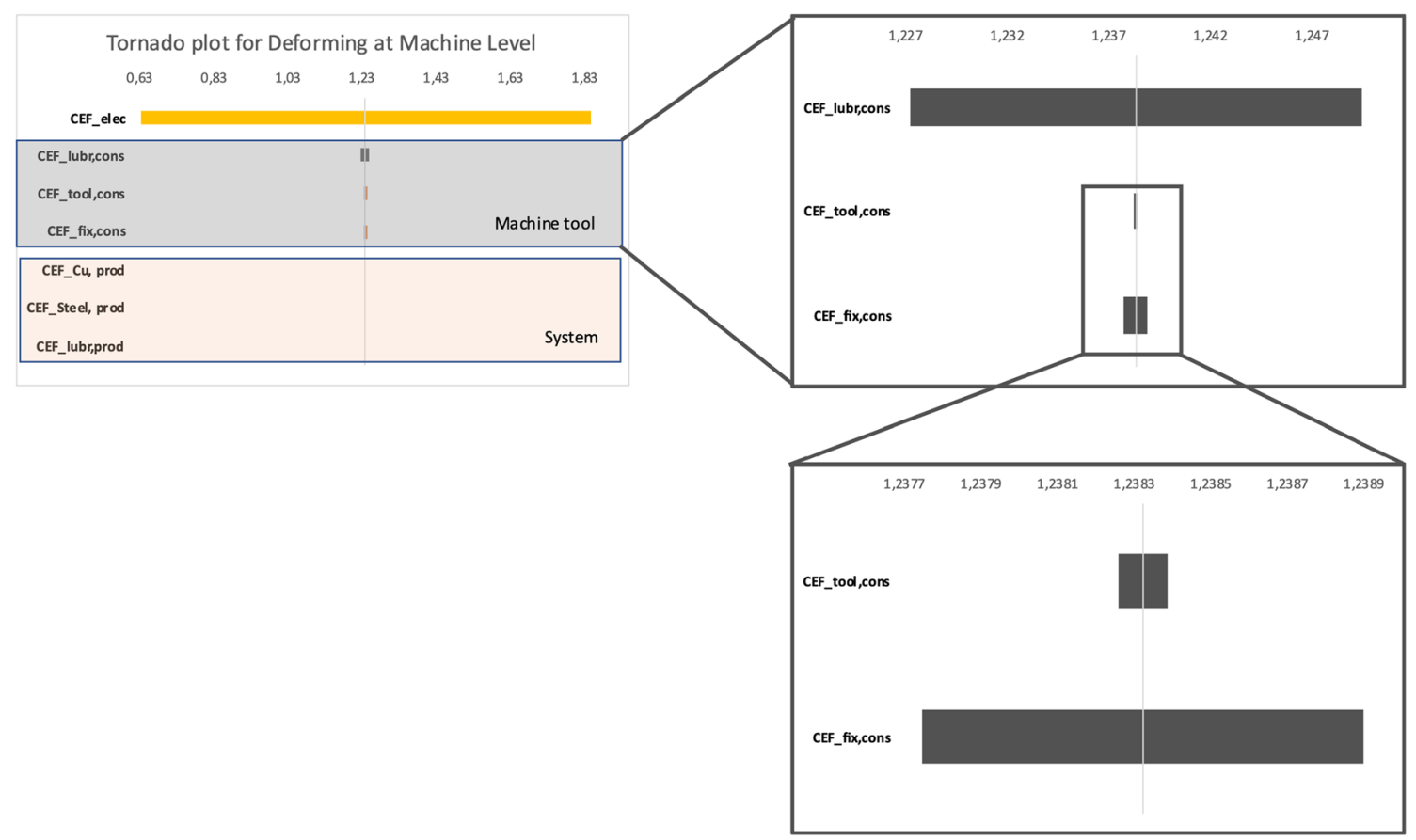

Fig. 10 Tornado plot for deforming at machine level (left), with zooming into the carbon emission factors at machine level (top right and bottom right). Equations (27)-(32) were used to calculate the carbon emissions at machine level (top left and bottom right), with the heaviest contributing at machine level being the carbon emission factor for electrical energy (left), followed by carbon emission factor of lubricant consumption (top right), carbon emission factor of fixture consumption (bottom right), and carbon emission factor of tool consumption (bottom right) 


\begin{tabular}{|c|c|c|c|}
\hline Level & Material removal & $\begin{array}{l}\text { Primary } \\
\quad \text { forming }\end{array}$ & Deforming \\
\hline Process & [37] [44] [61] & & \\
\hline $\begin{array}{l}\text { Machine } \\
\text { tool }\end{array}$ & $\begin{array}{l}{[21-23,29,30][35,36,39-41]} \\
{[45,48,49,55,57][59,62,65,67,68][79][81]}\end{array}$ & {$[84]$} & [86] [89] \\
\hline System & $\begin{array}{l}{[12,13,16,24,25][26][27,28][31][32][33,34][38][42][43][46,47,50][51][52][53][54,56]} \\
\quad[58][60][63,64][66][69][70][71,72][73][74][75][76,77][78][80][82][83]\end{array}$ & {$[20]$} & $\begin{array}{l}{[28,63,85,87,88]} \\
\quad[90][91][92]\end{array}$ \\
\hline
\end{tabular}

This approach provides an easy-to-follow and generalized methodology for calculating carbon emissions in manufacturing. However, it requires ways of decreasing the carbon emission factors which may not be feasible at all times. For example, reduction of carbon emission factor for electrical energy can be achieved via use of alternative or renewable power sources which may not be always easy to implement. Reduction of carbon emission factor for the production of raw materials can be done via use of recycled sources, but this may affect the quality of the final product. Therefore, one must identify the steps that can be modified according to the specific industry and the quality of the final product.

As already described (Sections 3 and 4), the carbon emission factors are qualitative parameters because they are related to how energy/material/consumable/tool is produced, consumed, disposed, or transported, while the energy efficiency, product design, and machine/consumable specifications are quantitative parameters and are related to the application in question. The different categories described in the next subsections are related to (1) material needed for the manufacturing, (2) machine specification used in the specific application, and (3) electrical energy consumed. The discussion is built upon the sensitivity analysis described in the previous sections. Extensive data analysis is not part of this paper's scope as this work provides a review of the literature and proposes a general framework to be used regardless the type of process. Future work on specific examples or processes will include further data analysis to identify the specific factors that contribute to carbon footprint, to define the optimizable parameters with the highest impact on carbon emissions and to provide process-specific alternatives of the general framework.

\subsection{Material needed for manufacturing}

Material needed for the manufacturing process is related to the raw or recycled material used as an input for each process. The effect of material selection is important, mainly because of the carbon emission factor for material production, but also because of quantitative parameters such as material removal rate in material removal process or mass of sand in primary forming process.
As seen from the tornado plots in the sensitivity analysis (Figs. 5 and 11), carbon emission factors of material production are among the heaviest contributing factors, with being the heaviest in material removal example and the second heaviest in the deforming example.

\subsubsection{Quantitative}

The quantitative parameters of the materials used in the calculation of carbon footprint are related to the design of the product, e.g., value of material removal and mass of chips in the material removal process $\left(M_{\text {chip }}\right)$, energy required for pressing, mass of steel, and mass of $\mathrm{Cu}$ used in the deforming. In the primary forming sensitivity analysis, the power and rate of compression at the process levels are indirectly related to material, while the mass of sand used and the surface area of the final beam are the quantitative parameters at the machine level. At the system level, the fractions of sand production and sand reclamation are important for the carbon emission calculation.

\subsubsection{Qualitative}

The qualitative parameters related to the material are the carbon emission factors for material production and material disposal. From the sensitivity analysis, the factor for the carbon emission factor for material production has the highest impact on the value of the carbon emissions from the system, as shown in the sensitivity analysis of the material removal (0.9051) and second highest for the deforming process ( 0.1415 for $\mathrm{Cu}$ and 0.1665 for Steel). The qualitative parameters for the primary forming are the fraction of clay $\left(\eta_{\text {cla }}\right)$ and sand $\left(\eta_{\text {san }}\right)$ which are strongly related to the final product specifications.

\subsection{Machine specifications}

Machine tool specifications are important for the carbon emissions at machine level, as shown in the tornado plots (Figs. 4 and 10). However, their contribution is not as strong as the contribution from electrical energy and material production at system level. 


\subsubsection{Quantitative}

The quantitative parameters of the machine tool in the material removal process are mainly concerning the feed rate and the cutting rate of the machines, as well as the volume of coolant consumed and the mass of cutting tool, along with their lifetimes. In addition, the power consumed during the air cutting, basic running, and shutting down are also qualitative parameters related to the machine tool and affect the carbon emissions from the machine tool.

For the primary forming, the quantitative parameters are the power and rate of compression at process level, while power and rate at the rest of steps related to the machine tool level are included. At the system level, the power and rate of mixing, reclamation, and production are included. In addition, temperature and heat capacity of sand and water are linked to the carbon emissions at machine tool level from the machine/ materials.

In cases of deforming, the quantitative parameters are the energy required for pressing, the time for forming, the lifetimes of forming tool and fixtures, and the volume of lubricant used.

\subsubsection{Qualitative}

The carbon emission factor of coolant production and disposal and of tool consumption are the qualitative factors of the machine tool that contribute to the carbon emissions. Carbon emission factor for coolant consumption is not a strong contributor the carbon emission, either at machine or system level, with sensitivity factors at 0.0058 and 0.0005 , respectively. The carbon emission factor of coolant disposal is the lowest contributor to the system carbon emissions with sensitivity factor of $4 * 10^{-5}$. The carbon emission factor of tool consumption $(0.3262)$ is the second largest sensitivity factor for the machine carbon emissions, while it is the third largest for the system carbon emissions (0.0286).

In the sensitivity example for primary forming of beams used in this review, the carbon emission factors are related to the use of coal (0.4849), crude oil $\left(10^{-7}\right)$, and diesel (0.1582). In the incremental sheet forming, the carbon emission factors for lubricant consumption, tool consumption, and usage of fixtures are the qualitative parameters. At both machine and system level, among the three carbon emission factors mentioned earlier, the strongest is the lubricant consumption, followed by usage of fixture and tool consumption.

\subsection{Energy needed for manufacturing}

In the non-phase changing processes (material removal and deforming), the tornado plots show that the carbon emission factor for electrical energy is one of the two top contributing factors (Figs. 3, 4, 5 for material removal and deforming (Figs.
9, 10, 11) at all levels (process, machine, system). In phasechanging processes (primary forming), there are also other sources for energy, mainly from coal, crude oil, nature gas, and diesel. As seen from the relevant tornado plots, at process (Fig. 6) and machine level (Fig. 7), electrical energy is still the main contributing factor, while the rest of the carbon emission factors are introduced at system level, with carbon emission factor of coal being the heaviest, surpassing even the contribution of carbon emission factor for electrical energy. Then the carbon emission factor of diesel follows, with crude oil and gas carbon emission factors contributing marginally to the carbon emissions of primary forming at system level (Fig. 8).

\subsubsection{Quantitative}

Regarding the material removal, there is an electrical energy factor for each process and material for the energy requirements $\left(k_{c}\right)$. In the primary forming example, the electrical energy consumed for clay and sand is related to the carbon emissions at system level, while in the deforming example, the energy consumed is used for annealing, bonding, and cutting at the machine level, besides the energy used for the process for both primary forming and deforming which is related to material and machine tool. There are also parameters indirectly related to electrical consumption, and these are related to material and machine specifications, but there is no straightforward relation between these parameters and the energy consumption. Most studies have been focusing in the making the processes more energy efficient ([18, 94]), which by its own is not enough to significantly decrease the carbon emission factors.

\subsubsection{Qualitative}

Carbon emission factor for electrical energy is calculated based on the contribution of coal, natural gas, and petroleum to the power grid, with the heaviest contribution coming from the coal. Therefore, a first step towards decreasing $C E F_{\text {elec }}$ is the reduction of coal as a power source while increasing the natural gas contribution.

Following Green Deal and EU carbon neutral 2050 directives, the power sources will become greener, therefore, decreasing carbon emission factor electrical energy. Notably, $C E F_{\text {elec }}($ solar $)=6 \mathrm{gCO} e / K W h$ and $C E F_{\text {elec }}($ wind $)=$ $4 \mathrm{gCO} 2 \mathrm{e} / \mathrm{KWh}$.

Carbon emission factor of electrical energy is calculated from the power grid and the source of power (coal, natural gas and oil)

$C E F_{\text {elec }}=\eta \cdot(112 \cdot \% C+49 \cdot \% N G+66 \cdot \% P)$

The value of the carbon emission factor for electrical energy depends on the country's emissions to produce 
electrical energy, which can differ from region to region. $C E F_{\text {elec }}$ can be decreased based on the way power is generated.

In the sensitivity analysis for the material removal, the electrical energy carbon emission factor is the only factor (sensitivity factor 1), while at machine level and system level, there are other factors; hence, the contribution of $C E F_{\text {elec }}$ is restricted, with sensitivity factors if 0.668 at machine level and 0.0585 for system level.

Regarding the primary forming example, similarly the carbon emission factor for electrical energy is the only factor for process and machine level, while its contribution drops at 0.357 at system level. There is also the gas consumption for certain parts of the primary forming, but it does not contribute to the carbon emissions at the system level $\left(6^{*} 10^{-9}\right)$.

For the deforming example, the carbon emission factor for electrical energy is the strongest factor (sensitivity factor 1), its influence decreasing at the following levels with sensitivity factors 0.981 for the machine level and 0.6445 at the system level.

\section{Conclusions}

Across all levels and processes examples, the energy-related carbon emissions are either the strongest or the second strongest contributing factors, therefore should be one of the first to be addressed on the way to carbon emission reduction. This can be approached by either using as less energy as possible, the usual approach in literature, or by considering the type of energy used and its environmental impact. The first approach is linked to a careful design of product and process planning and scheduling, along with using energy efficient equipment. The second approach is related to the carbon emission factors of energy consumption, which is how the energy is generated and what is their environmental impact. Using alternative power sources can decrease the carbon emission by up to $99 \%$, therefore making a huge impact on the carbon emission factors, much more than simply improving the energy efficiency of processes and equipment.

Another important fraction of carbon emissions, if not more important than electrical energy, derives from the material selection. In terms of quantitative parameters, a better selection of raw material and a careful design of the process will affect the carbon emissions at system level. Regarding the qualitative parameters, the carbon emission factors for material production depend on whether the material is extracted from ore or it is recycled, with recycling materials having much lower carbon emission factors.

The remaining carbon emissions are related to auxiliary equipment and coolant/lubricant usage, production, and disposal. Their impact is not as strong as the first two categories, but they are related to machine specifications or characteristics. Therefore, reduction of these carbon emissions can be done via usage of alternative liquids (e.g., use of nanofluid in machining [95] or use of vegetable ester-based biodegradable oil [96]), aiming to decrease the relevant carbon emission factor or via careful design of process requiring the least amount of coolant. In addition, selection of appropriate auxiliary tools has their own impact on carbon emissions, with studies showing that material type and velocity of cutting tools affecting the carbon emissions of the overall process [97].

In an order of high to low importance/contribution to carbon emissions, the order is consumption of electrical energy, production of raw material, and consumption/ disposal of tools and consumables. Therefore, if someone aims to decrease the carbon footprint of processes and products and create more sustainable processes and products, one must start by addressing and decreasing the electrical energy consumption and secondly by using recycled material, instead of extracting raw materials.

\section{Appendix 1}

All 79 papers that were included in this review for the background and state-of-the-art of carbon footprint calculation were categorized according to the process level and the level of details included in their approach. As described in Section 3.1, the three manufacturing levels are process, machine tool, and system, depending on the inclusion or not of carbon emissions from auxiliary equipment or from material production/disposal and transport to or from the industrial site. Classification of papers from literature search per level (process, machine tool, system) and per process (material removal, primary forming, deforming) can be found in the next table.

\section{Appendix 2. Sensitivity analysis and spider charts}

The calculation of the sensitivity analysis of the carbon emission factors was divided into two parts: (a) calculating the sensitivity factors which is located in this Appendix and making the spider charts and (b) using tornado plots to visualize the differences of the impact of different carbon emissions factors, which can be found in the main text, Section 4 .

Using the data from the relevant papers and investigating the effect of variations $( \pm 50 \%)$ of the carbon emissions factors on the carbon emissions per level (process, machine, system), the following spider charts were made. The slopes from the fitted lines provided the sensitivity factors can be found in the relevant tables in the Section dedicated to sensitivity analysis (Table 4 for material removal, Table 6 for primary forming, Table 8 for deforming). 

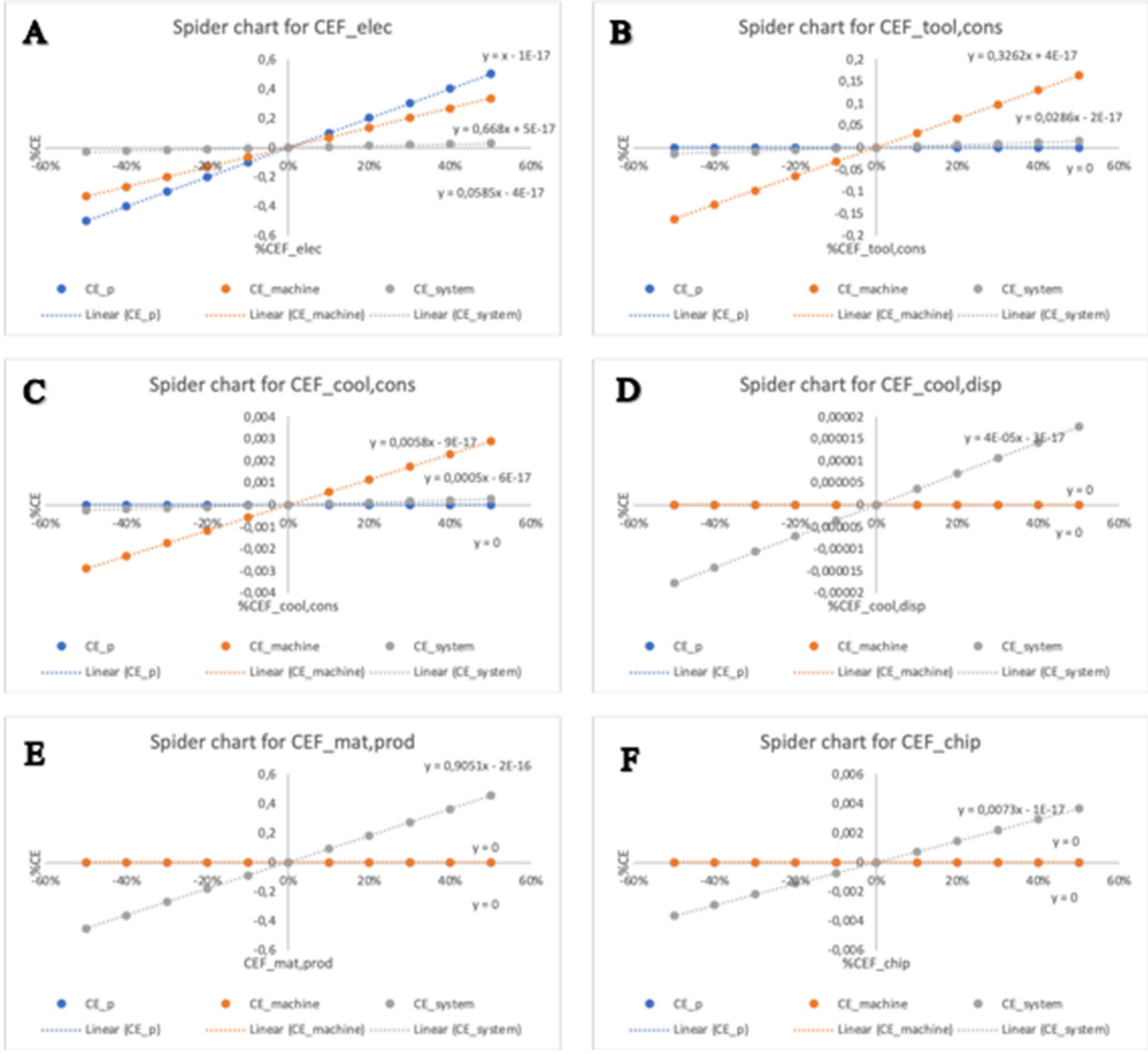

Fig. 12 Spider charts for material removal example, with variations on carbon emission factor of $\mathbf{A}$ electrical energy, $\mathbf{B}$ tool consumption, $\mathbf{C}$ coolant consumption, $\mathbf{D}$ coolant disposal, $\mathbf{E}$ material production, and $\mathbf{F}$

chip disposal. The slopes from the fitted lines provided with the sensitivity factors in Table 4 

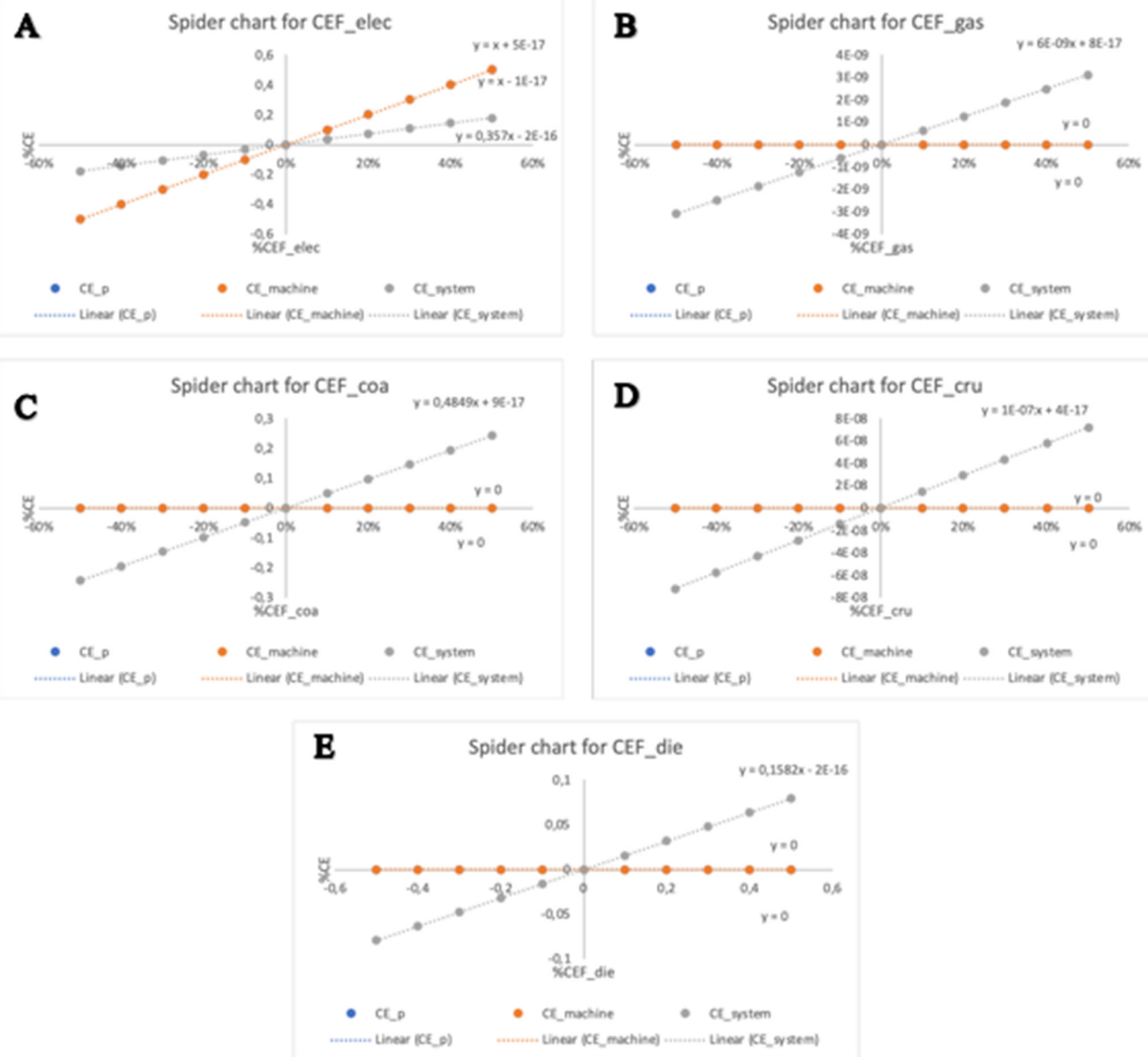

Fig. 13 Spider charts for primary forming, with variations on carbon emission factor of $\mathbf{A}$ electrical energy, $\mathbf{B}$ gas, $\mathbf{C}$ coal, $\mathbf{D}$ crude oil, and $\mathbf{E}$ diesel. The slopes from the fitted lines provided with the sensitivity factors in Table

Fig. 14 Spider charts for deforming example, with variations on carbon emission factor of (A) electrical energy, (B) lubricant consumption, (C) tool consumption, (D) fixture consumption, $(\mathbf{E}) \mathrm{Cu}$ production, (F) Steel production, and $(\mathbf{G})$ lubricant production. The slopes from the fitted lines provided with the sensitivity factors in Table 8 

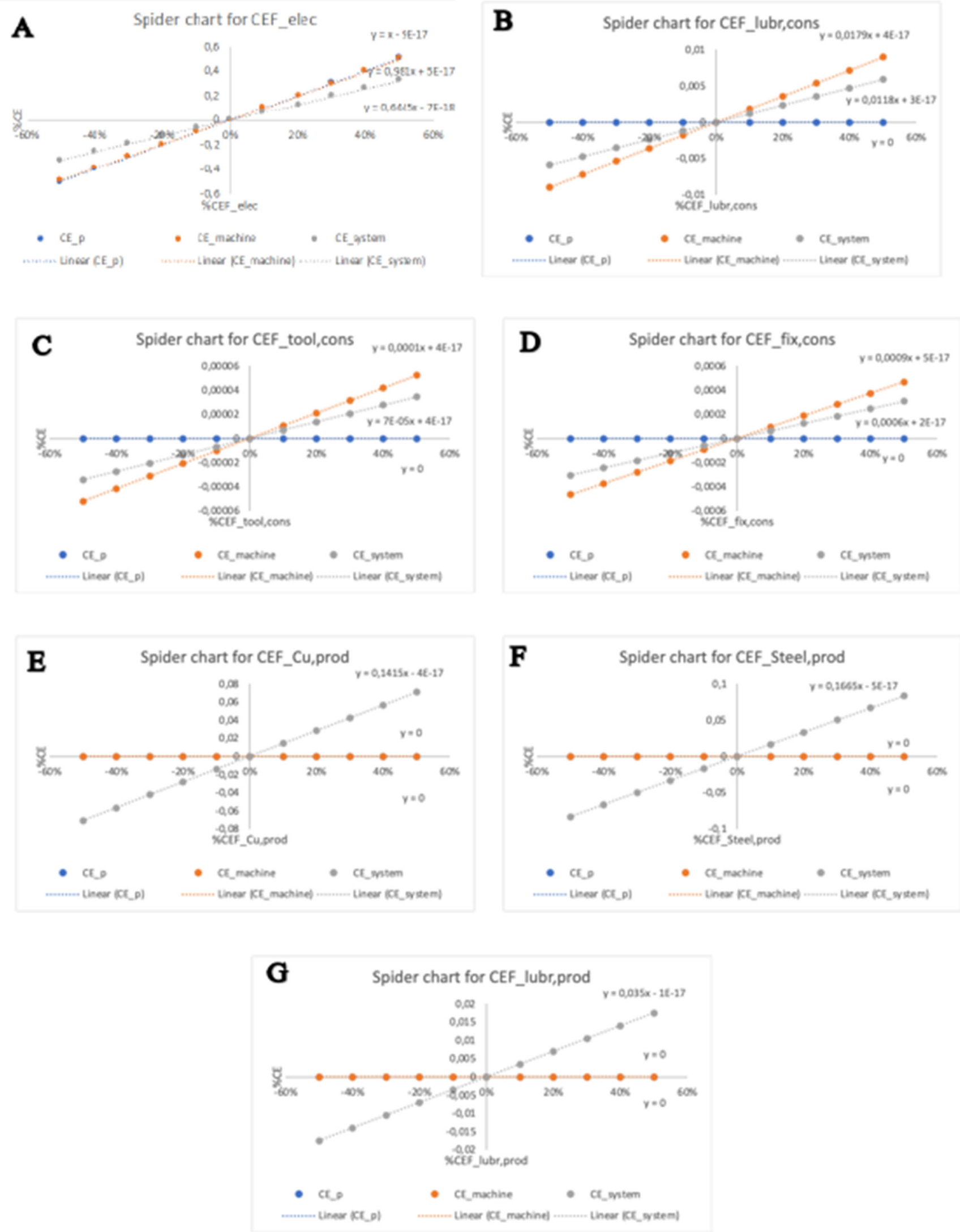
Code availability No code was performed for this work, hence there is no code available and this statement is not applicable in the context of this work.

Author contribution Vasiliki Christina Panagiotopoulou, formal analysis, methodology, visualization, and writing (original draft); Panagiotis Stavropoulos. conceptualization, funding acquisition, methodology, project administration, resources, and writing (review and editing); George Chryssolouris, conceptualization, funding acquisition, project administration, resources, and writing (review and editing).

Funding The work is partially supported by EU Project AVANGARD, grant number 869986 .

\section{Declarations}

Ethics approval Not applicable

Consent to participate Not applicable

Consent for publication Not applicable

Competing interests The authors declare no competing interests.

Open Access This article is licensed under a Creative Commons Attribution 4.0 International License, which permits use, sharing, adaptation, distribution and reproduction in any medium or format, as long as you give appropriate credit to the original author(s) and the source, provide a link to the Creative Commons licence, and indicate if changes were made. The images or other third party material in this article are included in the article's Creative Commons licence, unless indicated otherwise in a credit line to the material. If material is not included in the article's Creative Commons licence and your intended use is not permitted by statutory regulation or exceeds the permitted use, you will need to obtain permission directly from the copyright holder. To view a copy of this licence, visit http://creativecommons.org/licenses/by/4.0/.

\section{References}

1. Chryssolouris G (2006) Manufacturing systems: theory and practice. Springer Science \& Business Media

2. Ritchie $\mathrm{H}$, Roser $\mathrm{M}(2020) \mathrm{CO}_{2}$ and greenhouse gas emissions. Our world in data

3. S. P. Statistics (2019) https://ec.europa.eu/eurostat/statisticsexplained/index. $\mid$ php/Social_protection_statistics\#Social_ protection expenditure and GDP rates of change. Accessed 2019

4. EU Commission (2019) Reflection paper: towards a sustainable Europe by 2030

5. EU Commission 2050 Long-term Strategy

6. Pandey D, Agrawal M, Pandey JS (Jul) Carbon footprint: current methods of estimation. Environ Monit Assess 178(1-4):135-160. https://doi.org/10.1007/s10661-010-1678-y

7. Sotos ME (2015) GHG Protocol Scope 2 Guidance

8. Finkbeiner M, Inaba A, Tan R, Christiansen K, Klüppel H-J (2006) The new international standards for life cycle assessment: ISO 14040 and ISO 14044. Int J Life Cycle Assess 11(2):80-85

9. Wintergreen J, Delaney T (2007)

10. Athanasopoulou L, Bikas H, Stavropoulos P (2018) Comparative well-to-wheel emissions assessment of internal combustion engine and battery electric vehicles. Proc CIRP 78:25-30
11. Singh P, Madan J, Singh A, Mani M (2012) A computer-aided system for sustainability analysis for the die-casting process. [Online]. Available: http://asmedigitalcollection.asme.org/MSEC/ proceedings-pdf/MSEC2012/54990/1087/4427011/1087_1.pdf

12. Dahmus JB, Gutowski TG (2004) An environmental analysis of machining. American Society of Mechanical Engineers, Manufacturing Engineering Division, MED 15:643-652. https:// doi.org/10.1115/IMECE2004-62600

13. Lin W, Yu DY, Zhang C, Liu X, Zhang S, Tian Y, Liu S, Xie Z (2015) A multi-objective teaching-learning-based optimization algorithm to scheduling in turning processes for minimizing makespan and carbon footprint. J Clean Prod 101:337-347. https://doi.org/10.1016/j.jclepro.2015.03.099

14. Fang K, Uhan N, Zhao F, Sutherland JW (2011) A new approach to scheduling in manufacturing for power consumption and carbon footprint reduction. J Manuf Syst 30(4):234-240. https://doi.org/ 10.1016/j.jmsy.2011.08.004

15. Rajemi MF Keywords: energy and carbon footprint; machining; sustainable manufacturing ENERGY AND CARBON FOOTPRINT ANALYSIS FOR MACHINING TITANIUM Ti6Al-4V ALLOY

16. Bhanot N, Rao PV, Deshmukh SG (2016) An integrated sustainability assessment framework: a case of turning process. Clean Technol Environ Policy 18(5):1475-1513. https://doi.org/10. 1007/s10098-016-1130-2

17. Lu Q, Zhou G-H, Xiao Z-D, Chang F-T, Tian C-L (2018) A selection methodology of key parts based on the characteristic of carbon emissions for low-carbon design. Int J Adv Manuf Technol 94(9): 3359-3373

18. Fysikopoulos A, Stavropoulos P, Salonitis K, Chryssolouris G (2012) Energy efficiency assessment of laser drilling process. Phys Proc 39:776-783. https://doi.org/10.1016/j.phpro.2012.10. 100

19. Calefati P et al (2017) Energy efficient process planning system the ENEPLAN project to cite this version : HAL Id : hal-01472230 Energy Efficient Process planning System - the ENEPLAN Project

20. Liu H, Li B, Tang W (2019) Manufacturing oriented topology optimization of 3D structures for carbon emission reduction in casting process. J Clean Prod 225:755-770. https://doi.org/10.1016/j. jclepro.2019.03.163

21. Afsharizand B (2012) Investigation on quantitative assessment of energy consumption and the associated sustainability performance of CNC milling machines. Energy Efficiency (October)

22. Ahmad N, Enemuoh EU (2020) Energy modeling and eco impact evaluation in direct metal laser sintering hybrid milling. Heliyon 6(1). https://doi.org/10.1016/j.heliyon.2020.e03168

23. Altıntaș RS, Uluer MU, Ünver HÖ, Kılıç SE (2013) A theoretical energy consumption prediction model for prismatic parts using STEP AP224 features. Innovative Solutions: Proceedings of the 11th Global Conference on Sustainable Manufacturing, Berlin, Germany, September 23-25, 2013, pp 655-660

24. Awad MI, Hassan NM (2018) Joint decisions of machining process parameters setting and lot-size determination with environmental and quality cost consideration. J Manuf Syst 46:79-92. https:// doi.org/10.1016/j.jmsy.2017.11.004

25. Bao H, Guo S, Zhang L, Li X (2020) Research on process parameter collaborative optimization of non-metal laser cutting based on carbon emission modeling and intuitionistic fuzzy sets. Concurr Eng Res Appl 28(2):142-157. https://doi.org/10.1177/ 1063293X20919470

26. Beier J, Thiede S, Herrmann C (2017) Energy flexibility of manufacturing systems for variable renewable energy supply integration: real-time control method and simulation. J Clean Prod 141: 648-661. https://doi.org/10.1016/j.jclepro.2016.09.040

27. Bhanot N, Singh M, Pandey M, Sood P, Dhawan S (2019) A conceptual IoT framework for sustainability assessment of turning 
process with respect to quality and productivity control. Ind Eng $\mathrm{J}$ 12(4). https://doi.org/10.26488/iej.12.4.1181

28. Branker K A study of energy, carbon dioxide emissions and economics in machining: milling and single point incremental forming

29. Cai W, Lai K h (2021) Sustainability assessment of mechanical manufacturing systems in the industrial sector. Renew Sustain Energy Rev 135. https://doi.org/10.1016/j.rser.2020.110169

30. Cao WD, Yan CP, Wu DJ, Tuo JB (2017) A novel multi-objective optimization approach of machining parameters with small sample problem in gear hobbing. Int J Adv Manuf Technol 93(9-12): 4099-4110. https://doi.org/10.1007/s00170-017-0823-y

31. Deng Z, Lv L, Li S, Wan L, Liu W, Yan C, Zhang H (2016) Study on the model of high efficiency and low carbon for grinding parameters optimization and its application. J Clean Prod 137:1672-1681. https://doi.org/10.1016/j.jclepro.2016.03.022

32. Deng Z, Lv L, Huang W, Wan L, Li S (2020) Modelling of carbon utilisation efficiency and its application in milling parameters optimisation. Int J Prod Res 58(8):2406-2420. https://doi.org/10.1080/ 00207543.2019 .1633026

33. Ding H, Guo D, Cheng K, Cui Q (2014) An investigation on quantitative analysis of energy consumption and carbon footprint in the grinding process. Proceedings of the Institution of Mechanical Engineers, Part B: Journal of Engineering Manufacture 228(6): 950-956. https://doi.org/10.1177/0954405413508280

34. Dong Z, Liu Q, Li Q (2018) Optimization of machining process planning for carbon reduction. [Online]. Available: http:// asmedigitalcollection.asme.org/MSEC/proceedings-pdf/ MSEC2018/51357/V001T05A019/2520156/v001t05a019msec2018-6531.pdf

35. Frumuşanu G, Epureanu A (2015) Holistic approach of the optimization problem in manufacturing. Int J Mater Mech Manuf 4(1):3135. https://doi.org/10.7763/ijmmm.2016.v4.220

36. Gupta MK et al (2021) Environment and economic burden of sustainable cooling/lubrication methods in machining of Inconel-800. J Clean Prod 287. https://doi.org/10.1016/j.jclepro.2020.125074

37. Hatim QY, Saldana C, Shao G, Kim DB, Morris KC, Witherell P, Rachuri S, Kumara S (2020) A decision support methodology for integrated machining process and operation plans for sustainability and productivity assessment. Int J Adv Manuf Technol 107(7-8): 3207-3230. https://doi.org/10.1007/s00170-019-04268-y

38. Hu M, Sun Y, Gong Q, Tian S, Wu Y (2020) Multi-objective parameter optimization dynamic model of grinding processes for promoting low-carbon and low-cost production. Processes 8(1). https://doi.org/10.3390/pr8010003

39. Ic YT, Saraloğlu Güler E, Cabbaroğlu C, Dilan Yüksel E, Maide Sağlam H (2018) Optimisation of cutting parameters for minimizing carbon emission and maximising cutting quality in turning process. Int J Prod Res 56(11):4035-4055. https://doi.org/10.1080/ 00207543.2018.1442949

40. Jeswiet J, Kara S (2008) Carbon emissions and $\mathrm{CES}^{\mathrm{TM}}$ in manufacturing. CIRP Ann Manuf Technol 57(1):17-20. https:// doi.org/10.1016/j.cirp.2008.03.117

41. Jiang Z, Gao D, Lu Y, Liu X (2019) Optimization of cutting parameters for trade-off among carbon emissions, surface roughness, and processing time. Chinese Journal of Mechanical Engineering (English Edition) 32(1). https://doi.org/10.1186/s10033-019-0408-

42. Jiang Z, Gao D, Lu Y, Kong L, Shang Z (2021) Quantitative analysis of carbon emissions in precision turning processes and industrial case study. International Journal of Precision Engineering and Manufacturing - Green Technology 8(1):205-216. https://doi.org/ 10.1007/s40684-019-00155-9

43. Jiang Z, Gao D, Lu Y, Shang Z, Kong L (2020) Optimisation of cutting parameters for minimising carbon emissions and cost in the turning process. Proceedings of the Institution of Mechanical
Engineers, Part C: Journal of Mechanical Engineering Science. https://doi.org/10.1177/0954406220922872

44. Katchasuwanmanee K (2016) Investigation of the energy efficient sustainable manufacturing approach and its implementation perspectives

45. Khan AM, He N, Zhao W, Jamil M, Xia H, Meng L, Gupta MK (2020) Cryogenic-LN2 and conventional emulsion assisted machining of hardened steel: Comparison from sustainability perspective. Proceedings of the Institution of Mechanical Engineers, Part B: Journal of Engineering Manufacture:095440542097199. https:// doi.org/10.1177/0954405420971992

46. Khan AM et al (2020) Energy-based novel quantifiable sustainability value assessment method for machining processes. Energies 13(22). https://doi.org/10.3390/en13226144

47. Khan AM et al (2020) Energy-based cost integrated modelling and sustainability assessment of Al-GnP hybrid nanofluid assisted turning of AISI52100 steel. J Clean Prod 257. https://doi.org/10.1016/j. jclepro.2020.120502

48. Khan AM, Hussain G, Alkahtani M, Alzabidi A, Abidi MH, He N (2021) Holistic sustainability assessment of hybrid Al-GnPenriched nanofluids and textured tool in machining of Ti-6Al-4V alloy. Int J Adv Manuf Technol 112(3-4):731-743. https://doi.org/ $10.1007 / \mathrm{s} 00170-020-06371-\mathrm{x}$

49. Khan AM et al (2021) Assessment of cumulative energy demand, production cost, and $\mathrm{CO} 2$ emission from hybrid CryoMQL assisted machining. J Clean Prod 292. https://doi.org/10.1016/j.jclepro. 2021.125952

50. Khan AM et al (2021) Development of process performance simulator (PPS) and parametric optimization for sustainable machining considering carbon emission, cost and energy aspects. Renew Sustain Energy Rev 139. https://doi.org/10.1016/j.rser.2021. 110738

51. Khan AM, Anwar S, Jamil M, Nasr MM, Gupta MK, Saleh M, Ahmad S, Mia M (2021) Energy, environmental, economic, and technological analysis of al-gnp nanofluid-and cryogenic ln2assisted sustainable machining of ti-6al-4v alloy. Metals 11(1):122. https://doi.org/10.3390/met11010088

52. la Fé Perdomo I, Quiza R, Haeseldonckx D, Rivas M (2019) Sustainability-focused multi-objective optimization of a turning process. International Journal of Precision Engineering and Manufacturing - Green Technology. https://doi.org/10.1007/ s40684-019-00122-4

53. Li L, Deng X, Zhao J, Zhao F, Sutherland JW (2018) Multiobjective optimization of tool path considering efficiency, energysaving and carbon-emission for free-form surface milling. J Clean Prod 172:3311-3322. https://doi.org/10.1016/j.jclepro.2017.07. 219

54. Lin W, Yu DY, Wang S, Zhang C, Zhang S, Tian H, Luo M, Liu S (2015) Multi-objective teaching-learning-based optimization algorithm for reducing carbon emissions and operation time in turning operations. Eng Optim 47(7):994-1007. https://doi.org/10.1080/ 0305215X.2014.928818

55. Lin W, Tian G, Li Z, Zhang Y, Zhang C (2019) Flow shop scheduling with low carbon emission and variable machining parameters. Proceedings of the Institution of Mechanical Engineers, Part B: Journal of Engineering Manufacture 233(5):1561-1572. https:// doi.org/10.1177/0954405418782290

56. Liu ZY, Guo YB, Sealy MP, Liu ZQ (2016) Energy consumption and process sustainability of hard milling with tool wear progression. J Mater Process Technol 229:305-312. https://doi.org/10. 1016/j.jmatprotec.2015.09.032

57. Liu ZJ, Sun DP, Lin CX, Zhao XQ, Yang Y (2016) Multi-objective optimization of the operating conditions in a cutting process based on low carbon emission costs. J Clean Prod 124:266-275. https:// doi.org/10.1016/j.jclepro.2016.02.087 
58. Lv L et al (2019) A composite evaluation model of sustainable manufacturing in machining process for typical machine tools. Processes 7(2). https://doi.org/10.3390/pr7020110

59. Mulyadi IH, Balogun VA, Mativenga PT (2015) Environmental performance evaluation of different cutting environments when milling H13 tool steel. J Clean Prod 108:110-120. https://doi.org/ 10.1016/j.jclepro.2015.07.024

60. Ni H, Yan C, Cao W, Liu Y (2020) A novel parameter decision approach in hobbing process for minimizing carbon footprint and processing time. Int J Adv Manuf Technol 111(11-12):3405-3419. https://doi.org/10.1007/s00170-020-06103-1

61. Pervaiz S, Deiab I, Kishawy H (2016) A finite element based energy consumption analysis for machining AISI 1045 carbon steel using uncoated carbide tool. Adv Mater Process Technol 2(1):8392. https://doi.org/10.1080/2374068X.2016.1159033

62. Pervaiz S, Deiab I, Rashid A, Nicolescu M (2015) Prediction of energy consumption and environmental implications for turning operation using finite element analysis. Proceedings of the Institution of Mechanical Engineers, Part B: Journal of Engineering Manufacture 229(11):1925-1932. https://doi.org/10. 1177/0954405414541105

63. Priarone PC, Ingarao G, Settineri L, di Lorenzo R (2016) On the impact of recycling strategies on energy demand and $\mathrm{CO} 2$ emissions when manufacturing Al-based components. Procedia CIRP 48:194-199. https://doi.org/10.1016/j.procir.2016.03.044

64. Priarone PC, Robiglio M, Settineri L (2018) On the concurrent optimization of environmental and economic targets for machining. J Clean Prod 190:630-644. https://doi.org/10.1016/j.jclepro.2018. 04.163

65. Energy Analysis in Turning and Milling 2010 Mohamad Farizal RAJEMI School of Mechanical, Aerospace and Civil Engineering

66. Modelling O, Doi TP (2020) Modelling and optimization of machining processes towards economic and environmental sustainability Matteo Robiglio, no. August, 2020. https://doi.org/10. 6092/polito/porto/2674416

67. Salaam HA (2020) Sustainability performance model: a case study of pneumatic nipple hose connector. IOP Conference Series: Materials Science and Engineering 788(1). https://doi.org/10. 1088/1757-899X/788/1/012044

68. Sasindran V, Vignesh M, Arvind Krishna S, Madusudhanan A, Gokulachandran J (2019) Optimization of milling parameters of gun metal using fuzzy logic and artificial neural network approach. IOP Conference Series: Materials Science and Engineering 577(1). https://doi.org/10.1088/1757-899X/577/1/012010

69. Sihag N, Sangwan KS (2018) Development of a multi-criteria optimization model for minimizing carbon emissions and processing time during machining. Procedia CIRP 69:300-305. https://doi.org/ 10.1016/j.procir.2017.11.060

70. Uysal A, Caudill JR, Schoop J, Jawahir IS (2020) Minimising carbon emissions and machining costs with improved human health in sustainable machining of austenitic stainless steel through multiobjective optimisation. Int J Sustain Manuf 4(2-4):281-299. https://doi.org/10.1504/IJSM.2020.107154

71. Wang Y, Zhang H, Zhang Z, Wang J (2015) Development of an evaluating method for carbon emissions of manufacturing process plans. Discrete Dyn Nat Soc 2015:1-8. https://doi.org/10.1155/ 2015/784751

72. Wang Z, Zhang T, Yu T, Zhao J (2020) Assessment and optimization of grinding process on AISI 1045 steel in terms of green manufacturing using orthogonal experimental design and grey relational analysis. J Clean Prod 253. https://doi.org/10.1016/j. jclepro.2019.119896

73. Yin R, Cao H, Li H, Sutherland JW (2014) A process planning method for reduced carbon emissions. Int J Comput Integ Manuf 27(12):1175-1186. https://doi.org/10.1080/0951192X.2013. 874585
74. Yin R, Ke J, Mendis G, Sutherland JW (2019) A cutting parameterbased model for cost and carbon emission optimisation in a $\mathrm{NC}$ turning process. Int J Comput Integr Manuf 32(10):919-935. https://doi.org/10.1080/0951192X.2019.1667026

75. Zebala W, Struzikiewicz G, Słodki B (2020) Reduction of power consumption by chip breakability control in Ti6A14V titanium alloy turning. Materials 13(11). https://doi.org/10.3390/ma13112642

76. Zhang Y, Liu Q, Zhou Y, Ying B (2017) Integrated optimization of cutting parameters and scheduling for reducing carbon emissions. $\mathrm{J}$ Clean Prod 149:886-895. https://doi.org/10.1016/j.jclepro.2017. 01.054

77. Zhang C, Li W, Jiang P, Gu P (2017) Experimental investigation and multi-objective optimization approach for low-carbon milling operation of aluminum. Proceedings of the Institution of Mechanical Engineers, Part C: Journal of Mechanical Engineering Science 231(15):2753-2772. https://doi.org/10.1177/ 0954406216640574

78. Zhou G, Yuan S, Lu Q, Xiao X (2018) A carbon emission quantitation model and experimental evaluation for machining process considering tool wear condition. Int J Adv Manuf Technol 98(14):565-577. https://doi.org/10.1007/s00170-018-2281-6

79. Zhou G h, le Tian C, Zhang J j, Chang FT, Lu Q (2018) Multiobjective process route optimization considering carbon emissions. Int J Adv Manuf Technol 96(1-4):1195-1213. https://doi.org/10. 1007/s00170-018-1646-1

80. Zhou G, Lu Q, Xiao Z, Zhou C, Tian C (2019) Cutting parameter optimization for machining operations considering carbon emissions. J Clean Prod 208:937-950. https://doi.org/10.1016/j. jclepro.2018.10.191

81. Lu Q, Zhou GH, Zhao F, Li L, Ren YP (2019) Determination of shape and distribution of abrasive grains to reduce carbon emissions of honing process. J Manuf Sci Eng Trans ASME 141(2). https:// doi.org/10.1115/1.4041481

82. Tian C, Zhou G, Lu Q, Zhang J, Xiao Z, Wang R (2019) An integrated decision-making approach on cutting tools and cutting parameters for machining features considering carbon emissions. Int J Comput Integr Manuf 32(7):629-641. https://doi.org/10. 1080/0951192X.2019.1610575

83. Tian C, Zhou G, Zhang J, Zhang C (2019) Optimization of cutting parameters considering tool wear conditions in low-carbon manufacturing environment. J Clean Prod 226:706-719. https:// doi.org/10.1016/j.jclepro.2019.04.113

84. P. Singh, J. Madan, A. Singh,M. Mani A computer-aided system for sustainability analysis for the die-casting process," ASME 2012 International Manufacturing Science and Engineering Conference Collocated with the 40th North American Manufacturing Research Conference and in Participation with the Int. Conf., MSEC 2012, pp. 1087-1096, 2012. 10.1115/MSEC2012-7303

85. Al-Ghamdi KA, Hussain G (2017) On the CO2 characterization in incremental forming of roll bonded laminates. J Clean Prod 156: 214-225. https://doi.org/10.1016/j.jclepro.2017.04.047

86. Angihnelli

87. Bagudanch I, Garcia-Romeu ML, Sabater M (2016) Incremental forming of polymers: process parameters selection from the perspective of electric energy consumption and cost. J Clean Prod 112:1013-1024. https://doi.org/10.1016/j.jclepro.2015.08.087

88. Bagudanch I, Garcia-Romeu ML, Ferrer I, Lupiañez J (2013) The effect of process parameters on the energy consumption in single point incremental forming. Procedia Engineering 63:346-353. https://doi.org/10.1016/j.proeng.2013.08.208

89. J. J. Buis, J. W. Sutherland, F. Zhao Unit process life cycle inventory models of hot forming processes. ASME 2013 International Manufacturing Science and Engineering Conference Collocated with the 41st North American Manufacturing Research Conference, MSEC 2013, vol. 2, pp. 1-9, 2013. 10.1115/ MSEC2013-1054 
90. Ingarao G, Priarone PC, di Lorenzo R, Settineri L (2016) A methodology for evaluating the influence of batch size and part geometry on the environmental performance of machining and forming processes. J Clean Prod 135:1611-1622. https://doi.org/10.1016/j. jclepro.2015.11.041

91. Shen X, Chen L, Xia S, Xie Z, Qin X (2018) Burdening proportion and new energy-saving technologies analysis and optimization for iron and steel production system. J Clean Prod 172:2153-2166. https://doi.org/10.1016/j.jclepro.2017.11.204

92. Sidhu SS An approach towards sustainability analysis of diecasting product

93. Chryssolouris G, Papakostas N, Mavrikios D (2008) A perspective on manufacturing strategy: Produce more with less. CIRP J Manuf Sci Technol 1(1):45-52. https://doi.org/10.1016/j.cirpj.2008.06. 008

94. Pastras G, Fysikopoulos A, Stavropoulos P, Chryssolouris G (2014) An approach to modelling evaporation pulsed laser drilling and its energy efficiency. Int J Adv Manuf Technol 72(9-12): 1227-1241. https://doi.org/10.1007/s00170-014-5668-z

95. Abbas AT, Gupta MK, Soliman MS, Mia M, Hegab H, Luqman M, Pimenov DY (2019) Sustainability assessment associated with surface roughness and power consumption characteristics in nanofluid MQL-assisted turning of AISI 1045 steel. Int J Adv Manuf Technol 105(1):1311-1327

96. Zahoor S, Abdul-Kader W, Ishfaq K (2020) Sustainability assessment of cutting fluids for flooded approach through a comparative surface integrity evaluation of IN718. Int J Adv Manuf Technol 111(1):383-395

97. Li B, Cao H, Yan J, Jafar S (2017) A life cycle approach to characterizing carbon efficiency of cutting tools. Int J Adv Manuf Technol 93(9):3347-3355

Publisher's note Springer Nature remains neutral with regard to jurisdictional claims in published maps and institutional affiliations. 